\title{
POTENCIALIDADES PARA UN TURISMO SOSTENIBLE EN EL MARRUECOS MERIDIONAL
}

\author{
André Humbert \\ Université Nancy 2 \\ 3, place Godefroy de Bouillon \\ F - 54015 Nancy cedex \\ Andre.humbert@univ-nancy2.fr
}

\begin{abstract}
Resumen: Marruecos, que recibe bastantes turistas interesados por la visita de sus "ciudades imperiales" y sus zocos, tiene también un yacimiento de una riqueza extraordinaria en el campo del ámbito atlásico del Sur. No solamente ofrece el exotismo de sus paisajes naturales de montañas y desierto sino también todos los artefactos de una vieja civilización agraria adaptada a la aridez y al relieve. El inventario no exhaustivo de los recursos patrimoniales ofrecidos permite considerar las posibilidades de un desarrollo notable para un turismo cultural sostenible que beneficie a una amplia región desfavorecida por la deserción de gran parte de sus fuerzas vivas. Un circuito de turismo cultural real es propuesto como ejemplo y prueba de la factibilidad de una actividad que permite corregir los desequilibrios del país.
\end{abstract}

Palabras clave: turismo cultural, sostenibilidad, patrimonio, arquitectura popular, mediador cultural.

\begin{abstract}
If Morocco receives tourists interested in the visit of its "imperial cities" and its souks, the country also has a deposit of an extraordinary wealth in the countryside of the Atlas mountains in the South. It not only offers the exotism of its natural mountain landscapes and desert but also all the objects or buildings of an old agrarian civilization adapted to the dryness and the relief. The nonexhaustive inventory of the offered patrimonial resources allows to consider the possibilities of a considerable development for a sustainable cultural tourism that benefits to an ample underprivileged region by the desertion of great part of its active forces. A circuit of real cultural tourism is proposed like example and test of the feasibility of an activity that allows to mitigate the imbalances of the country.
\end{abstract}

Keywords: cultural tourism, sustainability, patrimony, popular architecture, cultural mediator. 
Marruecos recibe de 4 a 5 millones de visitantes cada año y, poco antes de la crisis mundial, el gobierno de Muhammad VI pretendía atraer a 10 millones en 2010, con un programa muy ambicioso de ordenación de los litorales tanto mediterráneo como atlántico. Los caudales turísticos que quedan por debajo de los flujos que acuden a Túnez son de dos tipos radicalmente diferentes. En efecto, si Marruecos es para poblaciones europeas nórdicas (Alemanes, Suecos, Daneses, etc.) un destino sobre todo de sol invernal, es también, y desde hace mucho tiempo, un país de turismo cultural gracias a la frecuentación muy sostenida de sus grandes ciudades históricas, calificadas de imperiales. El proyecto gubernamental reciente cuenta más con una frecuentación litoral que con un reforzamiento significativo del turismo urbano. Sin embargo, si el modelo tunecino, o el de la fachada española que mira a África hace soñar a los marroquíes, no deben de olvidar que su larga costa atlántica no puede, en invierno, y quizá, ni siquiera en el verano, ofrecer un agua que apetezca por su calor: Agadir o Esauira tienen magníficas playa de arena pero, incluso en junio o julio, el viento frío de la tarde puede obligar uno a vestirse de jersey. Sin embargo estas playas del Sur tienen, tierra adentro, un campo atlásico atractivo poco visitado que podría representar un triunfo formidable para el desarrollo de otro tipo de turismo (Figura 1).

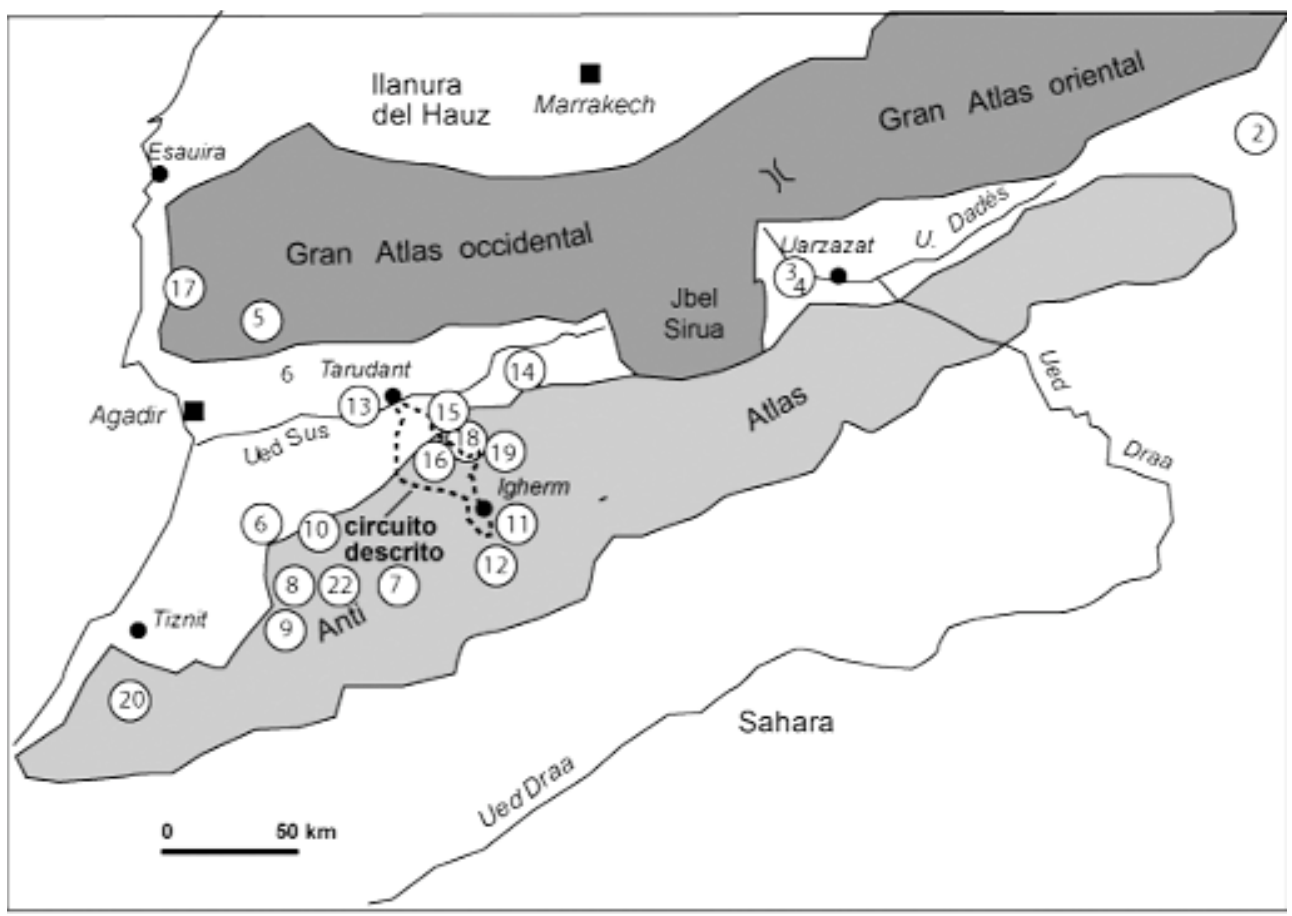

Figura 1. Marruecos meridional atlásico y localización espacial de los documentos de las figuras. 


\section{Un potencial cultural muy diverso}

Al sur del Gran Atlas, Marruecos no posee grandes ciudades cuya antigüedad e historia compleja, como Fes o Marrakech, hayan podido producir una riqueza urbana y arquitectónica. Solo la antigua capital de la dinastía Saadí, Tarudant, ofrece un conjunto interesante de murallas y una estructura urbana de medina hoy, desgraciadamente, en vía de transformación completa. Más al sur, Tiznit, "la Puerta del Desierto" presenta un recinto comparable. Reciben visitantes pero siempre desde Agadir donde los hoteles proponen excursiones de un día sin pernoctación en lugares donde el equipamiento hotelero no se ha desarrollado, esterilizado por la hotelería gadiri sometida a los operadores que ofrecen "paquetes" con vuelo y media pensión a una clientela cautiva.

\subsection{Paisajes y hábitat rural}

Sin embargo, si el Sur no dispone de un gran patrimonio urbano, sí ofrece unos recursos naturales y sobre todo la riqueza inestimable de la impronta humana en los paisajes del campo; el campo de la llanura del río Sus y aún más el de las montañas del Atlas donde una humanidad de campesinos sedentarios o sedentarizados ha ordenado el fondo de los valles y las vertientes con el mosaico de sus parcelas, con sus obras hidráulicas y sus hábitats, reflejo del medio ambiente y de un modelo particular de sociedad. La simple contemplación de estos paisajes da al viaje del turista un valor estético y cultural indiscutible. Debemos a la verdad de reconocer que este turismo contemplativo y emocional no está ausente de los programas ofrecidos pero es siempre como una actividad extra y marginal de las estancias en los hoteles de playa. Dos o tres excursiones son propuestas bien en el Gran Atlas para visitar las cascadas en el relieve kárstico de la tribu de los Ida ou Tanane, bien en el Anti-Atlas occidental, en Tafraút, donde existe un relieve caótico de granito. Estos dos sitios de visita han aprovechado la proximidad relativa de Agadir y sobre todo la existencia de carreteras asfaltadas establecidas por la administración francesa. Muchos más sitios de interés hubieran podido alimentar unos circuitos de paisajes emblemáticos pero, demasiados retirados en el interior de la montaña o asequibles solo por pistas dificilísimas, han sido desatendidos por los operadores turísticos. Más al este, más allá del potente macizo volcánico del Sirua, el Sureste presahariano de la región de UarzazatZagora, se ha beneficiado de la ilusión del desierto y los oasis, atrayendo a una clientela particular que busca el exotismo a la vez que un ambiente de aventura. En este turismo muy alejado de las playas ya hay, en parte, una mirada cultural sobre los paisajes de oasis y sobre las formas peculiares del hábitat, el de los qsur (sing. qsar) y de las qasabat (sing. qasba). Estas formas, muchas veces confundidas, son la expresión muy llamativa de lo que fue $-\mathrm{y}$ es, en parte todavía-, la organización de una sociedad contrastada de antiguos esclavos negros -los haratín - y de sus maestros 
bereberes, blancos sedentarizados. Los qsur, son pueblos amurallados, frecuentemente edificados sobre una planta regular que albergan comunidades de campesinos, colonos o trabajadores en los oasis que pertenecieron a los grupos nómadas blancos (Fig. 2). Las qasabat son grandes casas señoriales parecidas a castillos con sus torres de esquinas. Indudablemente son las casas de los maestros construidas cuando estos se sedentarizaron: son casas fuertes que acogen -o acogían- a un número importantísimo de individuos del mismo linaje. Cuando la familia aumentaba el qsar se elevaba entre sus murallas de tierra hasta alcanzar un cuarto o un quinto piso. Normalmente las qasabat estaban aisladas pero existen, a veces, concentraciones que forman pueblos enteros, entre los cuales uno de los más famosos es el de Aitbenhaddou, cerca de Uarzazat, que ha sido declarado patrimonio de la humanidad

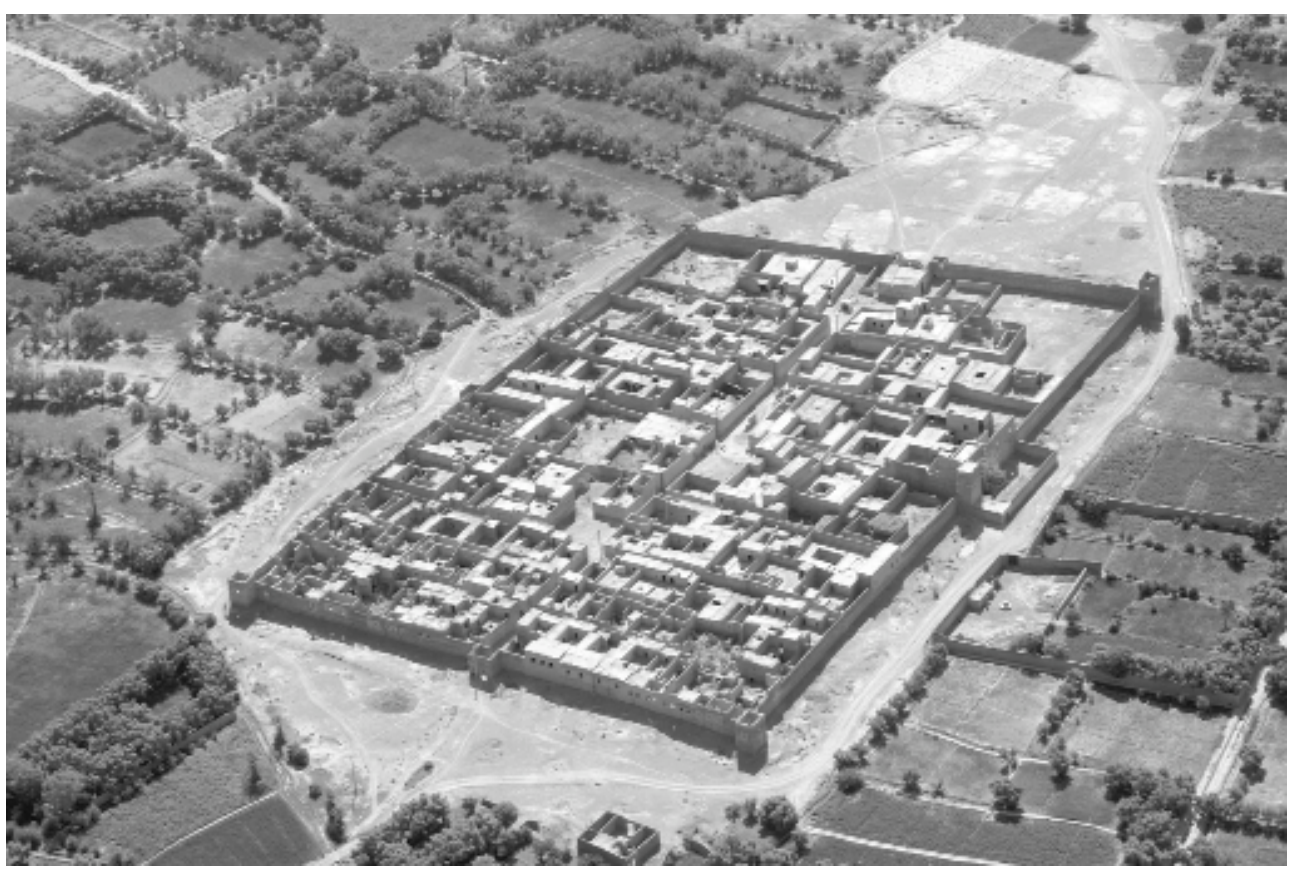

Figura 2. Qsar del oasis del Tafilalet, cerca de Errachidia.

Esta vista aérea de un qsar del Tafilalet pone en evidencia los principales caracteres de este tipo de hábitat de los oasis del Sureste marroquí. A la inversa del hábitat tradicional de la mayoría del campo del país estos pueblos tienen una organización muy rigurosa, que solo pude explicar una voluntad planificadora de los amos de la tierra. Los qsur de esta región albergan a una población de antiguos esclavos negros (haratín) que fueron, antaño, instalados en medio de los oasis bajo la custodia y la vigilancia de los que los compraron. La muralla debía de proteger un capital humano contra la codicia de otros grupos de nómadas. 
y que atrae un gran número de turistas (Fig. 3 y 4). Es un excelente ejemplo de turismo teóricamente cultural, aunque hay que lamentar la pésima explotación verdaderamente cultural de las visitas, por falta de un nivel de mediación cultural suficiente: demasiadas veces las explicaciones son meramente anecdóticas. Sin embargo, el impacto económico empieza a ser notable a través de la acogida hotelera que se ha desarrollado en los núcleos principales (Uarzazat, Zagora, Aitbenhaddou...); pueden ser hoteles grandes de cadenas internacionales pero también son, a veces, empresas privadas cuyos promotores son locales o por lo menos marroquíes con raíces locales; pero el más interesante es la apertura al turismo de grandes casas, particularmente de qasabat, que sus poseedores han transformado en casa de huéspedes después de introducir elementos de confort que no tenían (aseos, duchas, cuarto de baño). Esta evolución es más que notable, pues traduce una cierta apertura de una

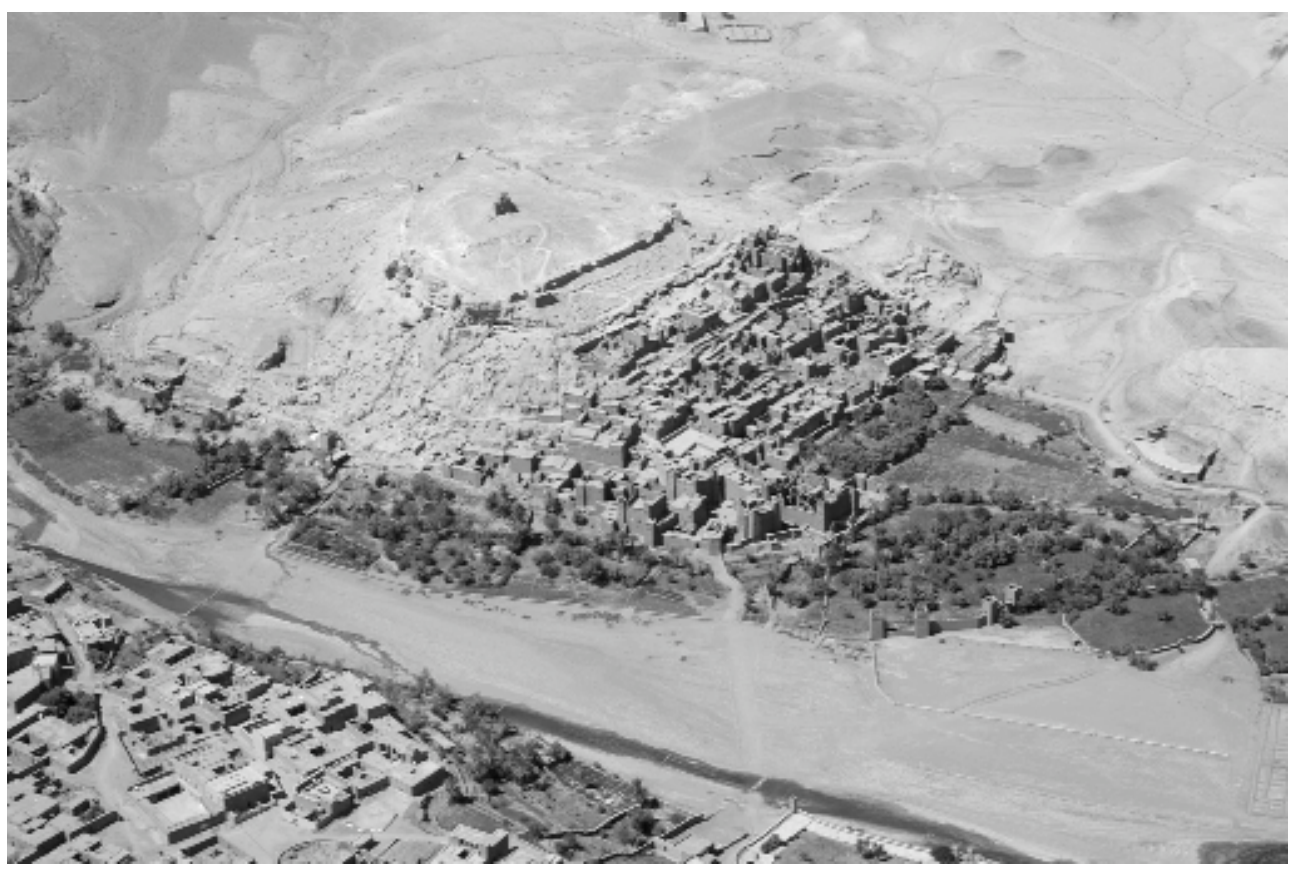

Figura 3. El qsar de Aïtbenhaddou, en el Gran Atlas central (provincia de Uarzazat). Este pueblo, situado a la salida de un valle de montaña, es conocido como qasba de Aïtbenhaddou. Es, en realidad, un qsar reuniendo en su recinto amurallado un gran número de qasabat con sus torres de esquinas. El pueblo está dominado por lo que fue, seguramente, una fortaleza establecida para controlar una de las rutas importantes de travesía del Atlas central, aquella del puerto que permite pasar a la zona de Marrakech (tizi n'Tichka). El sitio de Aïtbenhaddou es uno de los más visitados del Sur marroquí y ha sido declarado patrimonio de la Humanidad por la UNESCO. 


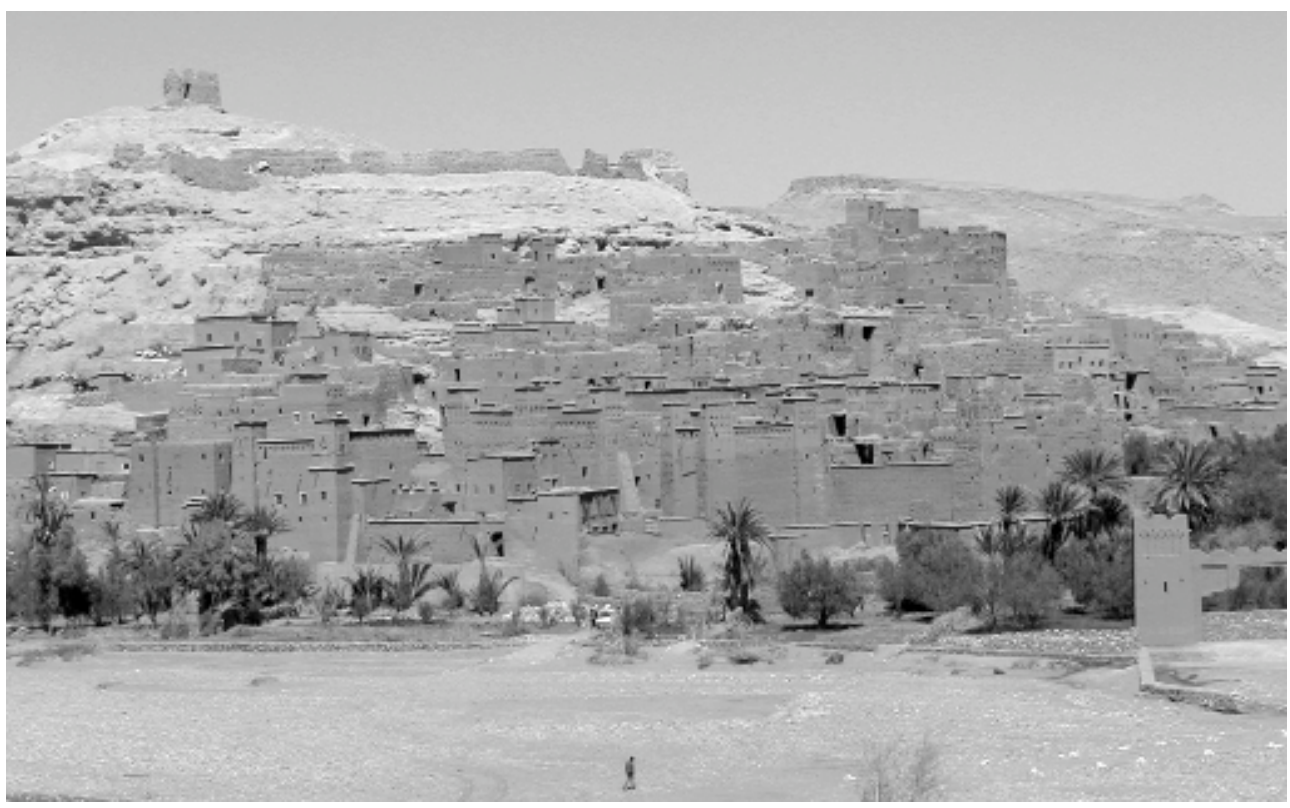

Figura 4. El qsar de Aïtbenhaddou visto desde la orilla del ued Unila.

Visto desde el suelo, el qsar revela mejor su estructura con sus qasabat agrupadas cuya estructura se observa perfectamente con sus altas torres en los ángulos. Estas casas de familias numerosas son de tierra a pesar de su altura: el confinamiento en un recinto establecido desde el principio ha obligado a buscar espacio verticalmente y las generaciones se superpusieron en vez de yuxtaponerse.

sociedad muy cerrada, aunque nunca la familia se abre al punto de acoger a los forasteros en su seno.

Un turismo de tipo europeo que puede radicar hasta el campo más alejado de las ciudades se instala poco a poco a medida que se desarrolla la red de carretera o a lo largo de los ejes ya existentes, pero quedan amplias zonas, principalmente de montaña, que permanecen al margen de esta evolución y que, sin embargo, poseen un extraordinario potencial para un turismo cultural. En efecto, el aislamiento prolongado de las montañas atlásicas ha petrificado sus paisajes en una situación casi medieval que los da un valor cultural inestimable. La palabra cultural no puede ser empleada de una manera más idónea para hablar de lo que el campo del Atlas puede ofrecer. Los paisajes, los artefactos de la vida cotidiana, los usos de los habitantes, son la expresión de una civilización campesina que merece interés y cuidado al momento que puede desvanecerse como consecuencia de una apertura brutal al mundo exterior. 
Los paisajes de montaña son directamente asequibles al turista de una manara meramente contemplativa. Sus componentes pueden ser naturales como el caos de Tafraút o como las gargantas tan frecuentes en el Gran Atlas, pero también en el AntiAtlas central u oriental. Sin embargo, los paisajes adquieren un valor realmente cultural con las construcciones humanas seculares: pueblos colgados, ordenación de las vertientes con impresionantes conjuntos de bancales, oasis del fondo de los valles, etc. El simple entusiasmo producido por la contemplación de las obras de una civilización exótica da un contenido cultural a una excursión fuera de las arenas de la playa. Pero este turismo adquiere una dimensión mucho más cultural aún si el visitante se detiene para penetrar en la intimidad de los paisajes e intentar comprender la lógica funcional y sociológica de los espacios que descubre (Fig. 5). Observando desde un mirador un pueblo en el fondo de un valle, se asombra del desorden incomprensible no solamente de la planta general del hábitat sino también de la disposición de los múltiples elementos de que se componen las casas. La "culturalidad"

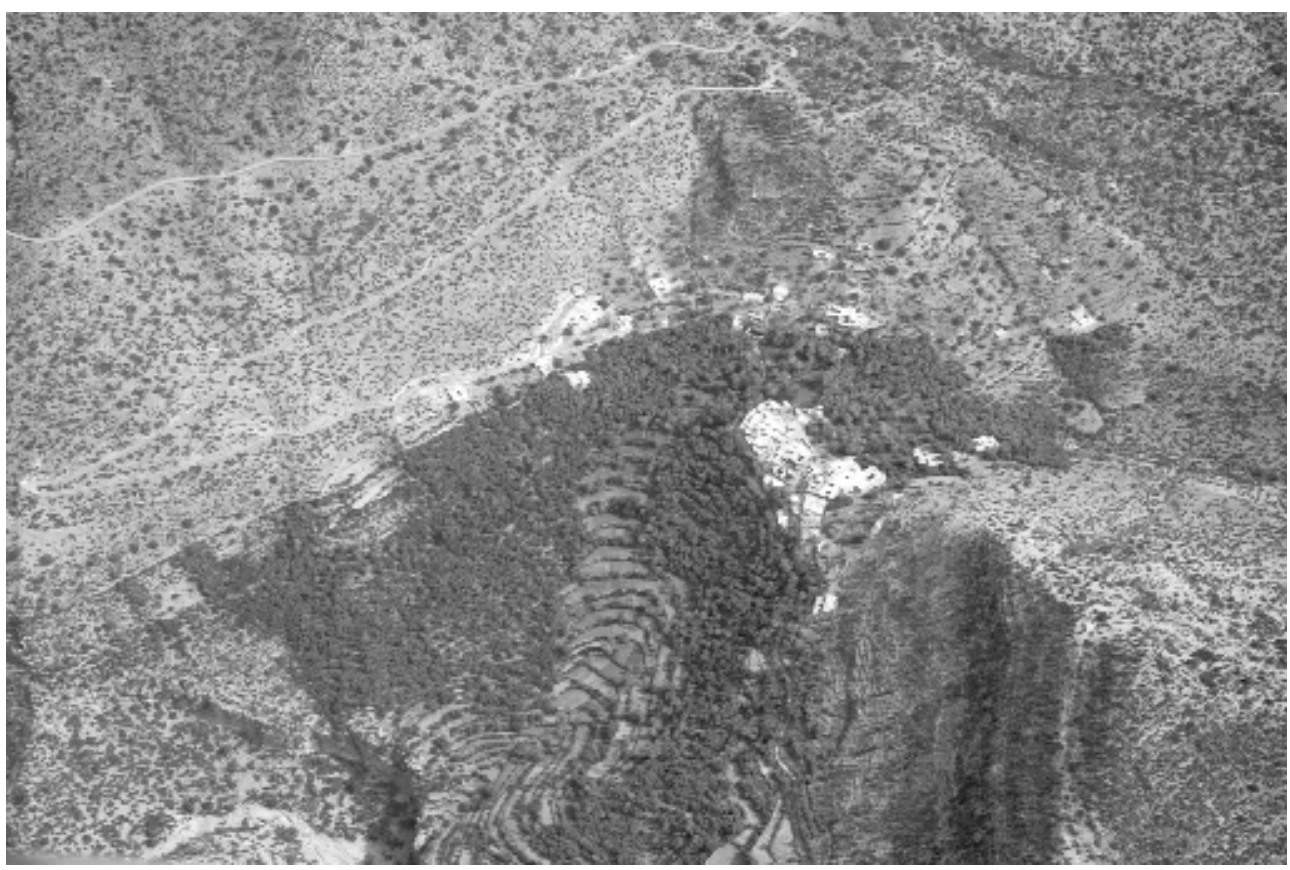

Figura 5. Vega colgada en la vertiente del Gran Atlas occidental.

Este paisaje es un buen ejemplo de los que se pueden admirar en las montañas del Sur marroquí. Admirar, y explicar, por qué y cómo un grupo humano ha transformado un medio natural dificilísimo de colonizar. Un guía ilustrado puede enseñar mucho, a un grupo de turistas, sobre el funcionamiento de este tipo de sistema geográfico. 
adquiere una calidad sin comparación si se le explica al turista que esta anarquía aparente no es el resultado de la incompetencia arquitectónica de la sociedad rural local sino de la organización social del grupo humano así como de la relación jurídica de los hombres con el suelo. La fuerte cohesión del linaje familiar reúne en la misma casa - pero no bajo el mismo techo- un número importante de individuos de varias generaciones y esta aglutinación progresiva ha necesitado la construcción, progresiva también, de nuevos elementos de la casa, añadidos al núcleo primitivo (Fig. 6). El uso del terrado para cubrir las casas da a cada elemento una autonomía constructiva que permite una disposición y una forma muy independiente en relación con los demás edificios. Si añadimos que en la sociedad islámica tradicional el derecho de usar el suelo no se adquiere previamente a la construcción sino como consecuencia de una

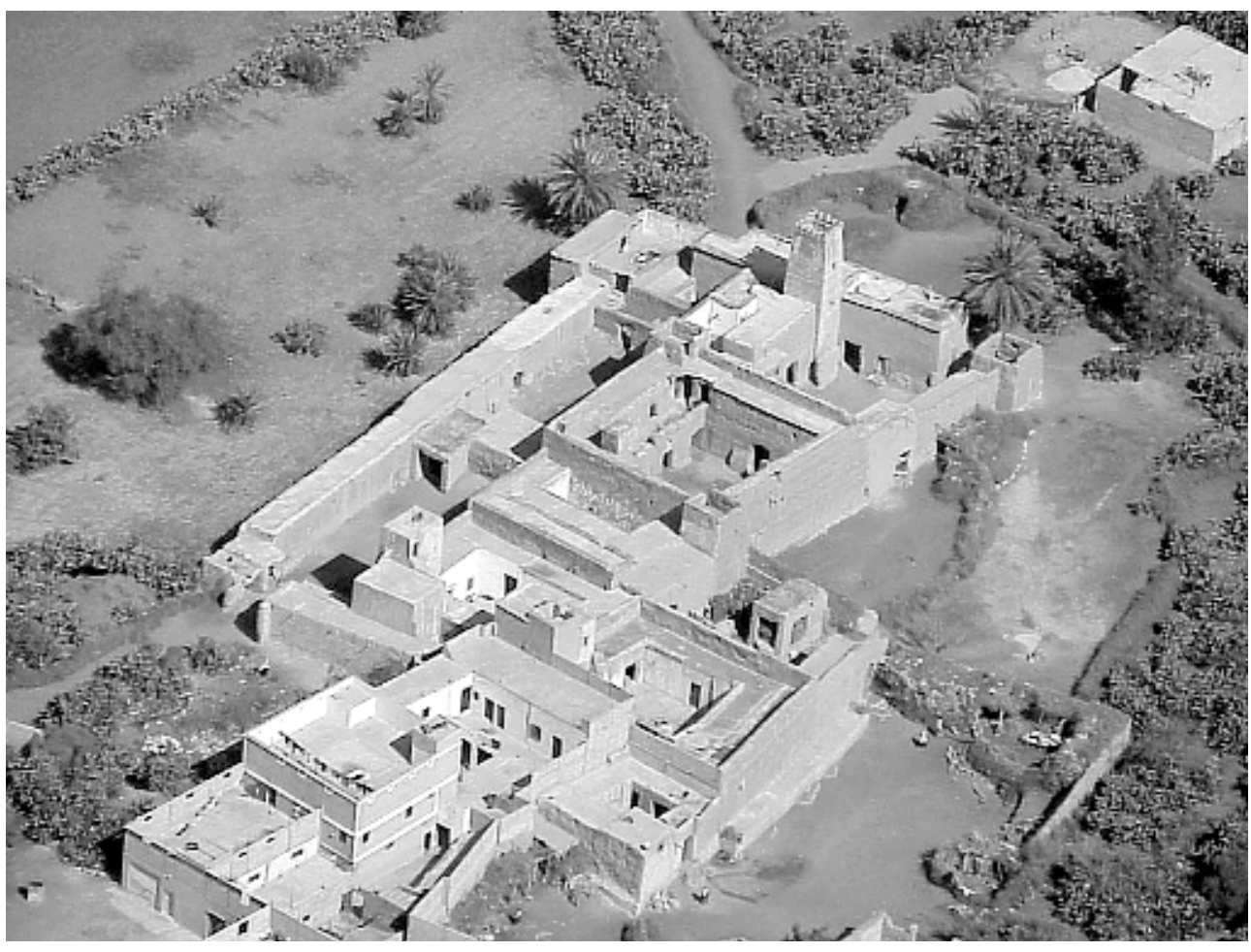

Figura 6. Casa grande de un linaje familiar en el piedemonte del Anti-Atlas central. Esta casa es un buen ejemplo de hábitat campesino en el cual vive - o vivía - un grupo familiar numeroso de tres o cuatro generaciones bajo la autoridad del pater familia. El núcleo inicial está en la parte alta de la foto con su torre de vigía (el borj). A medida que aumentaba el número de hogares, se añadían nuevos elementos más o menos cúbicos con sus habitaciones y su patio. Todos los hijos varones casados se quedan normalmente con su familia en la casa del padre. 
edificación cualquiera, de la plantación de unos árboles, de la excavación de un pozo, de un aljibe, etc. La anarquía observada es la consecuencia consustancial, pues, de la organización de una sociedad y no de su retraso tecnológico. Enseñando al visitante extraño es cambiar su mirada y su opinión.

\subsection{Artefactos populares}

Esta aproximación general de una sociedad a través de su hábitat puede ser completada por la comprensión de elementos patrimoniales más íntimos de la vida del grupo, como los aljibes que, en muchas comarcas del Anti-Atlas, son las únicas fuentes de agua "potable" para las familias campesinas (Fig. 7). El mismo pueblo puede

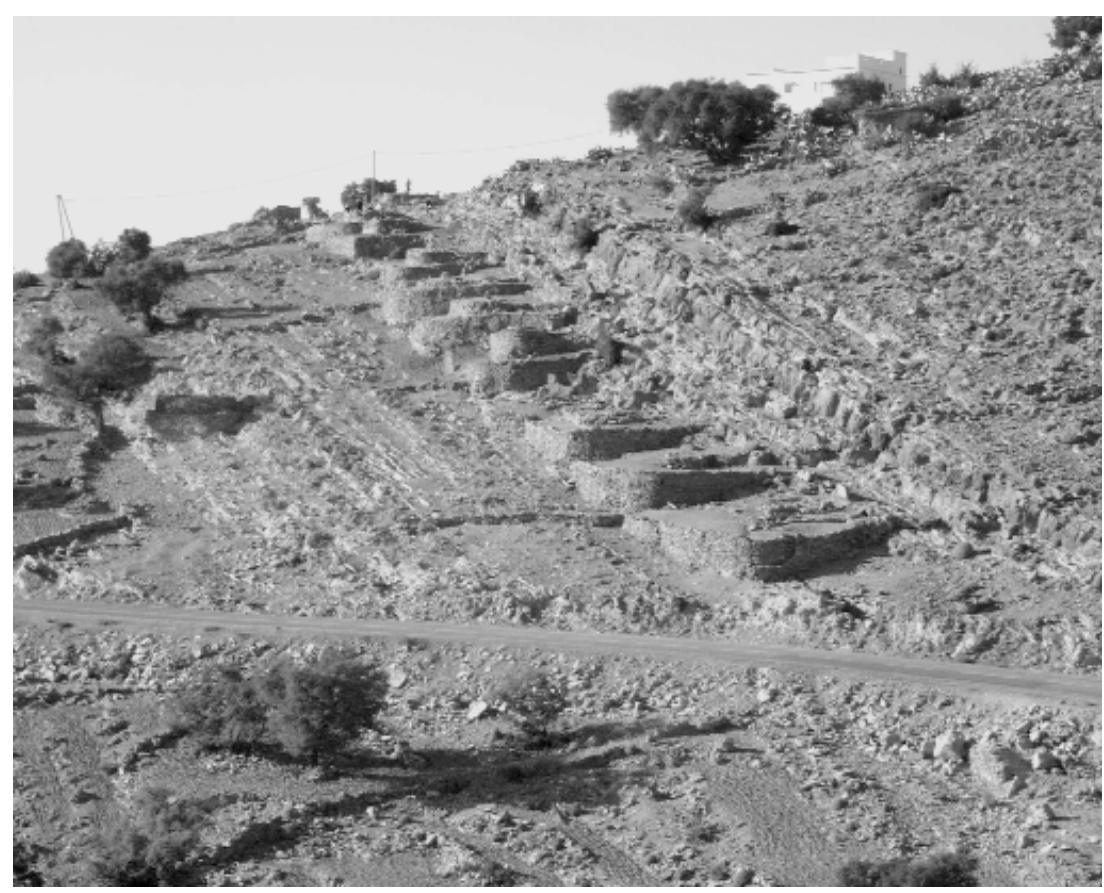

Figura 7. Aljibes (tinudfay) en cadenas en el Anti-Atlas central.

Una parte importante del Anti-Atlas central es conocida por el nombre de bled tanutfi, es decir el país de los aljibes .Es que, fuera de los fondos de raros cañones donde aparecen los nacimientos, esta montaña carece completamente de agua durante la mayor parte del año. La única solución es la recuperación del agua de las escorrentías durante la breve temporada de las lluvias. En esta foto puede uno observar un dispositivo de aljibes en cadena, construido en la vertiente próxima a un pueblo, aprovechando la estructura geológica para concentrar las mayores cantidades posibles. 
tener más de un centenar de estos artefactos cavados en la roca, cubiertos por una bóveda de lozas y reunidos por una red compleja de regueras que los alimentan, en cadena. Pero, el elemento patrimonial el más emblemático -y espectacular- de gran parte del Atlas occidental, principalmente del Anti-Atlas, es una obra colectiva amenazada de destrucción por su desuso casi general actual. Se trata del agadir (plur. igudar) o granero colectivo fortificado (Fig. 8). Estos magníficos edificios de tierra compactada o de piedras son la herencia de una época de inestabilidad social durante la cual las montañas agrícolas del Atlas estaban sometidas, periódicamente, a unas razias de parte de poblaciones nómadas del sur. El agadir es una fortaleza, a veces colocada en un cerro, pero no siempre, que sirve -o servía- para varias aldeas de los

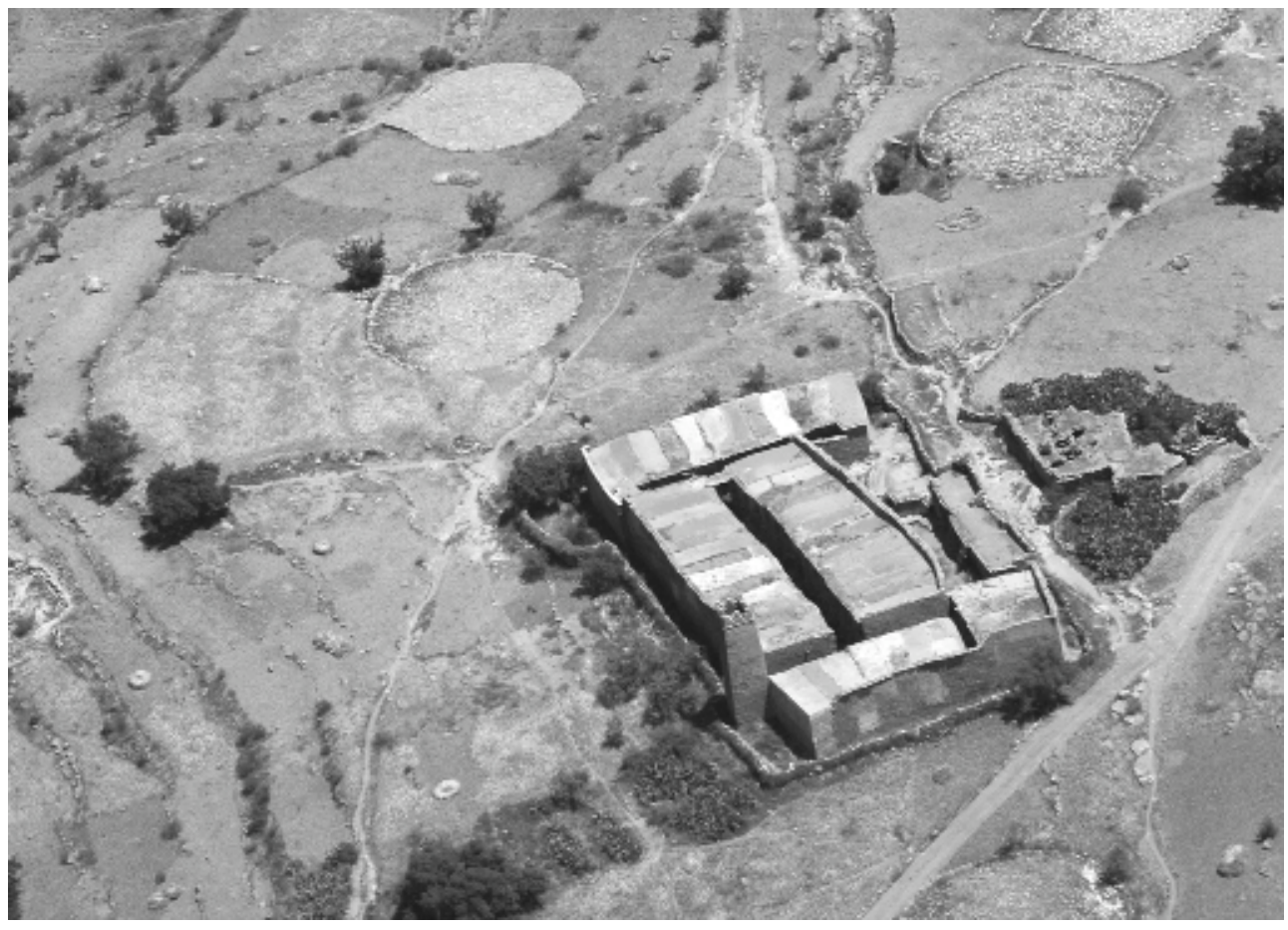

Figura 8. Agadir del Anti-Atlas central

Este granero colectivo corresponde a un tipo bastante difundido y sencillo con cuerpos paralelos separados por una calle (ver foto del interior). En este caso, probablemente con el aumento de la población, el edificio ha sido completado por dos cuerpos suplementarios transversales. En esta foto se observa perfectamente la estructura de los demás elementos del Agadir: su corral exterior al granero propiamente dicho, la entrada con la casa del portero (amín), la única torre de vigía (borj) y el recinto bastante simbólico que rodea el conjunto. Cerca del Agadir podemos reconocer los grandes discos de las eras del pueblo y, por la derecha, las ruinas de una pequeña mezquita rural. 
alrededores. La parte principal es el granero propiamente dicho compuesto de un gran número de casetas o compartimientos -se conoce uno de casi tres cientos- rigurosamente idénticas superpuestas, generalmente en tres pisos, y alineadas a ambos lados de una calle (Fig. 9 y 10). El plano puede ser más complicado con varios cuerpos o con una disposición alrededor de un corral central. El agadir comporta otros elementos que atestiguan su vida autónoma, por lo menos en su periodo de funcionamiento climácico. Existe una muralla exterior con torres de vigía en las cuatro esquinas y con una puerta única monumental que da paso a un amplio corral en el cual está la casa del portero y vigilante del agadir, el amín. En este espacio existía también, casi siempre, la tienda de un joyero judío porque el agadir servía igual-

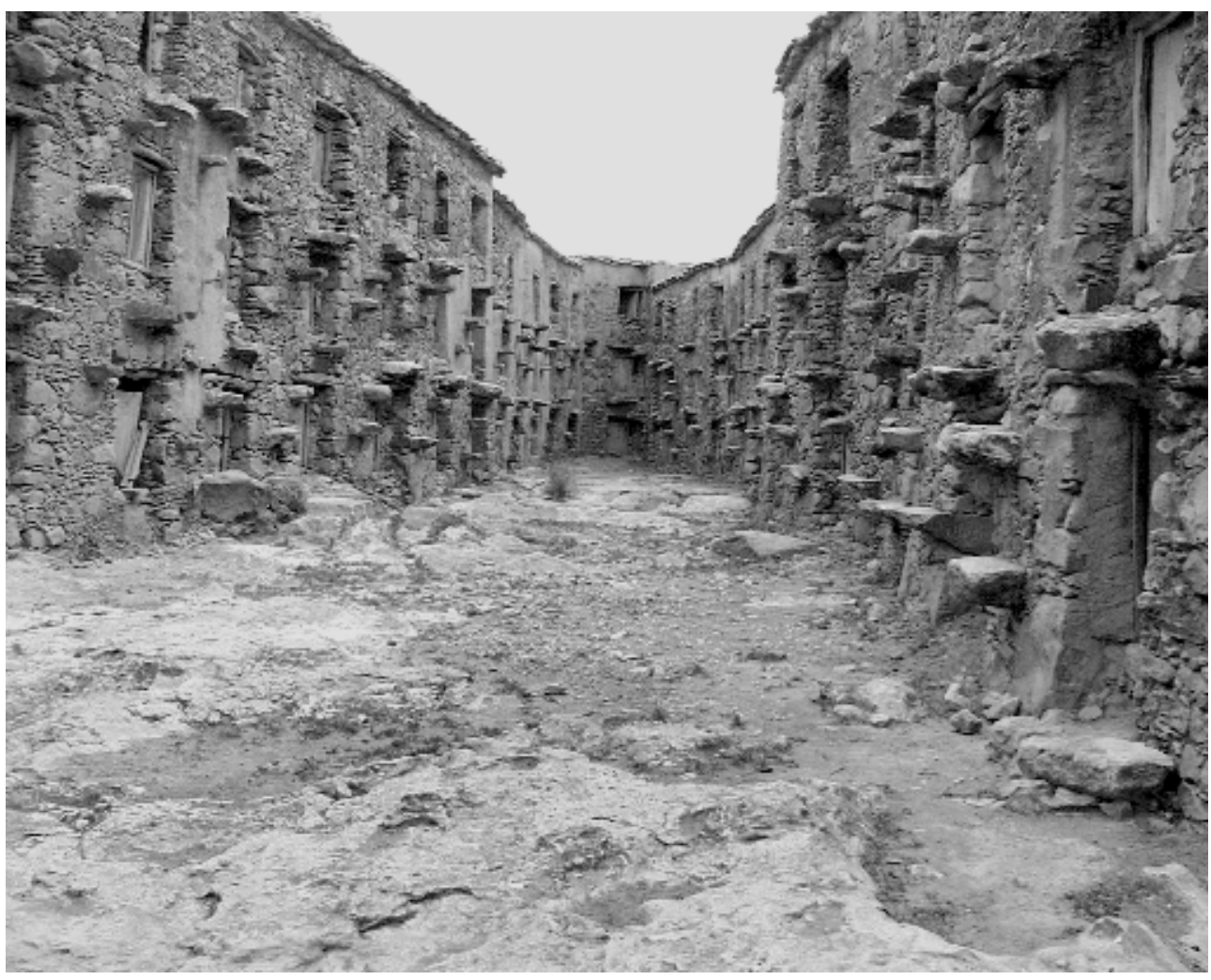

Figura 9. Interior de un agadir del Anti-Atlas central.

La estructura de los igudar puede variar mucho. Este es de un tipo sencillo con una o dos calles principales sobre la cual se abren los compartimientos del granero con sus puertas de madera. Las lozas grandes que salen del muro sirven de escalera para alcanzar los pisos superiores. Cuando el Agadir es construido en tierra, el acceso a las casetas superiores se hace con escaleras de madera confeccionadas con troncos de arganes o de palmeras. 


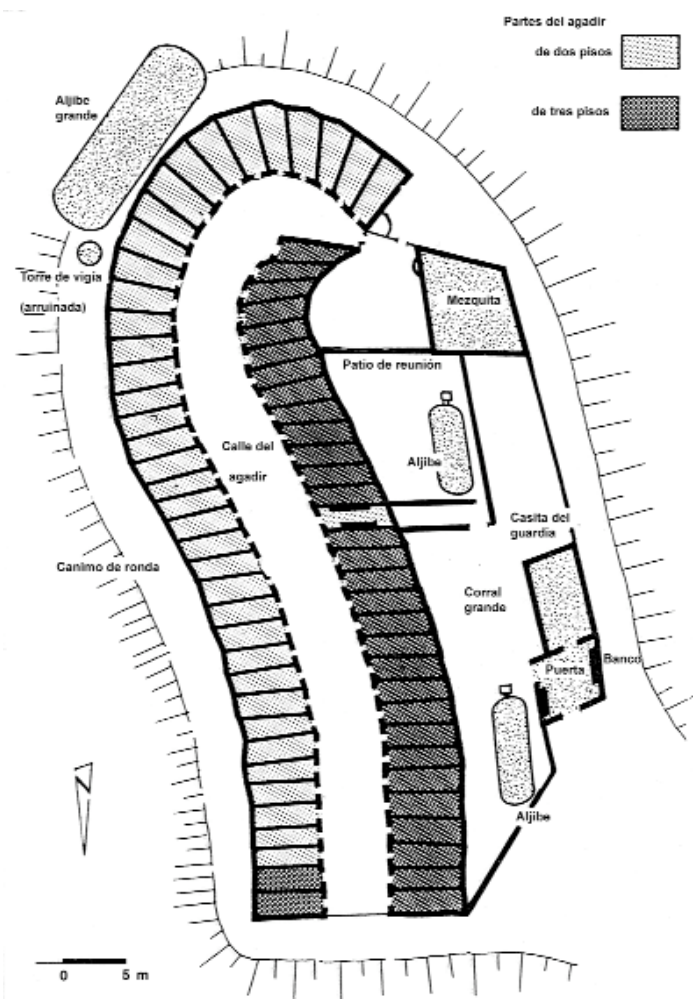

Figura 10. Plano de un agadir del Anti-Atlas central.

Este gran Agadir de casi 200 compartimientos está colocado en el borde septentrional del AntiAtlas en un cerro que domina la llanura del río Sus. Su plano permite analizar la morfología del edificio y comprender la complejidad de su funcionamiento asi como el el papel que desempeñó en la sociedad campesina. Hoy, el Agadir de Umsdikt está casi totalmente arruinado y ya no sirve.

mente para guardar las joyas y otros bienes preciosos de los campesinos. Dentro del recinto, también había una mezquita -más bien una sala de oración- para acoger a los visitantes que se encontraban en el agadir a la hora del rezar y sobre todo, antaño, para los guardias encargados de defender el granero (ineflas). Pero, en el Islam, no hay plegaria sin agua y, en el corral, se encuentran varios aljibes (tanutfi) que también servían para la familia del portero, para los campesinos de paso y sus bestias. Hasta principios del siglo XX, los aljibes han podido permitir a unos grupos refugiados en el granero sobrevivir durante el tiempo que duraba el peligro de las razias. El agadir es, pues, no solamente un bello edificio, un modelo de arquitectura popular, es también un producto cultural emblemático que más allá de la admiración 
debe despertar un interés intelectual, una reflexión sobre la organización colectiva y la supervivencia de las sociedades. La calidad de un turismo cultural depende de la capacidad del mediador de adquirir el conocimiento histórico-geográfico necesario y, sobre todo, la aptitud didáctica para adaptarlo a la realidad del terreno.

\subsection{Usos campesinos}

A pesar de las condiciones físicas dificilísimas de la montaña atlásica (aridez, pendientes, suelos) es una tierra de labradores y no solo de pastores como se podría pensar. La mayoría de la tierra en el Anti-Atlas es de secano, solo capaz de producir cebada y almendras, con rendimientos que pueden parecer ridículos para los campesinos europeos, aún inferiores a los rendimientos de las peores tierras de Castilla o de Aragón antes de los progresos agronómicos. A pesar de -o quizá en razón aesta pobreza, los hombres de la montaña (ibudraren, sing. abudrar), han hecho una verdadera obra constructiva en sus terrazgos, edificando en las vertientes millares de kilómetros de bancales, a la vez para mantener la tierra y para recuperar las ínfimas cantidades de agua que caen de un cielo poco generoso. Cuando, por fortuna, un nacimiento permite el regadío, en la ladera y el fondo del valle nace un oasis con sus terrazas construidas con sumo esmero y cuya tierra está labrada solo con el azadón. Más allá del paisaje producido por la pena de los hombres hay, pues, prácticas, usos agrícolas que no solamente son meros gestos de cultivar sino que también son la expresión de una cultura que puede interesar al turista por poco que un mediador cultural le explique el funcionamiento de los sistemas de los cuales puede observar el cuerpo a través de los paisajes. Cuando, en Europa, los sistemas tradicionales han desaparecido casi por completo o se han "museificado", aquí es todavía posible ver en la "naturaleza" como se organiza un turno de agua, como se mide el tiempo de regadío con un reloj de sol o un tazón de cobre (tanast) (Fig. 12 y 11) o como se cosecha a mano antes de trillar con una manada de burros en la era (anrar).

Podríamos todavía hablar de otros usos y de otros artefactos de esta sociedad montañesa ligada al pastoralismo, a la cosecha de las nueces de argán en el monte y su transformación en aceite, al manejo de las almazaras arcaicas para convencer aún más, si fuera necesario, de la riqueza cultural del patrimonio de un campo que parece olvidado por el movimiento de la mundialización.

Ahora bien, el problema es de saber cómo favorecer un turismo cultural de calidad a la vez que un desarrollo endógeno sostenible. No cabe duda que la montaña se está abriendo gracias a la acción conjugada del Estado marroquí y de las asociaciones campesinas ampliamente alimentadas en recursos económicos por la diáspora bereber de las ciudades del Norte del país y el extranjero. Observamos con qué rapidez asombrosa se multiplican los kilómetros de asfalto que alcanzan ahora los pue- 


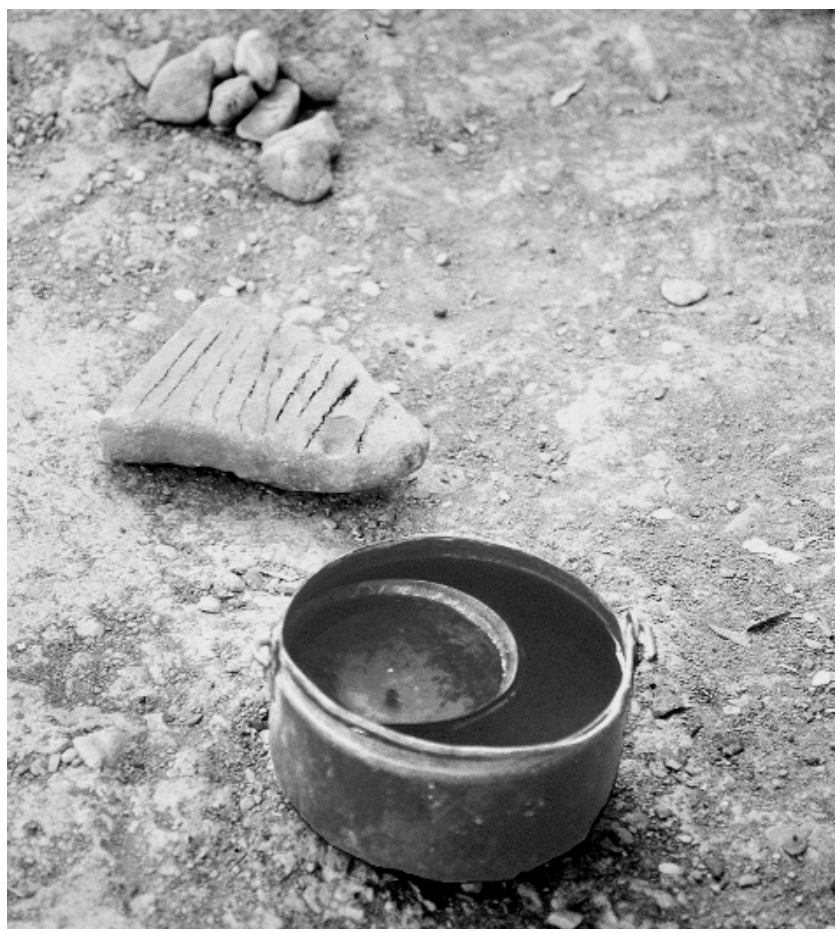

Figura 11. Una tanast de la región de Igherm (Anti-Atlas central).

Para el reparto del agua en los turnos (nuba), con tiempos breves, se utiliza este tazón de cobre perforado en su parte inferior. El tiempo que tarda en hundirse por completo es de unos minutos hasta una veintena, en función del tamaño del recipiente y del agujero. El amazzal (el aguador) cuenta cuidadosamente el número de tazones con las piedras cuyo montónse adivina, y cada diez marca una barra con un pedazo de carbón en la "pizzara" que tiene al lado. En el momento de la foto, a finales de la jornada, ya ha cumplido la maniobra un centenar de veces.

blos más retirados. Ya está asequible gran parte de los bienes culturales de que acabamos de hablar. Los obstáculos físicos han prácticamente desaparecido. Ya pueden entrar los turistas. Pero también se imponen algunas preguntas. ¿Cómo organizar los flujos turísticos hacia la montaña? ¿En qué estructuras acoger a los visitantes durante su estancia tan breve que sea? ¿Cómo asegurar la calidad cultural de las visitas? Sobre todo ¿Cómo proceder para que el beneficio económico de este turismo no vaya a enriquecer más a los grandes operadores internacionales y, al contrario, contribuya al renacimiento económico y humano de la región? En fin, ¿Cómo evitar que la apertura de la montaña no se traduzca por la invasión de formas de ocupación del espacio que produzcan la degradación del patrimonio cultural? 


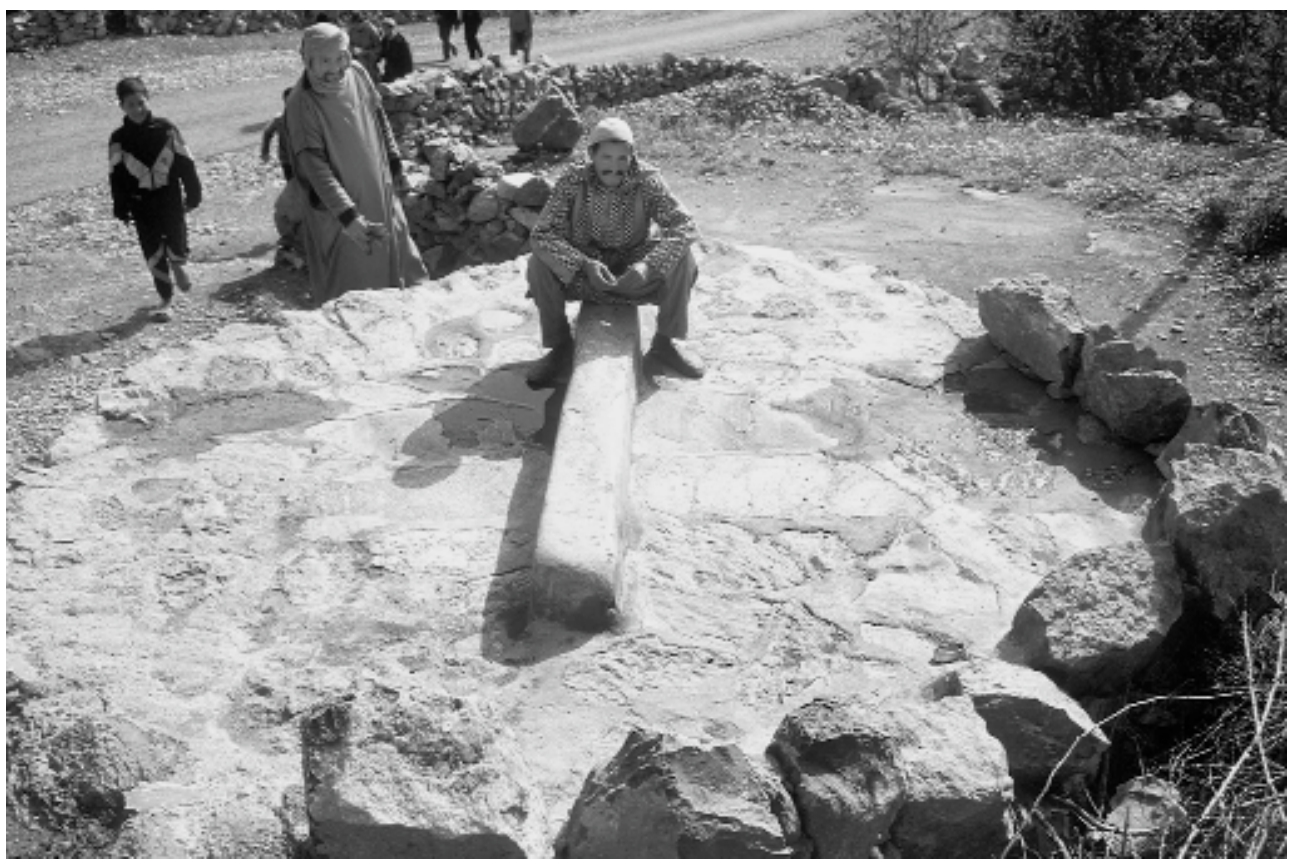

Figura 12. Reloj de sol en el Anti-Atlas central (región de Igherm).

Orientado norte-sur, el muro bajo del sistema proyecta su sombra a ambos lados sobre una plataforma horizontal hecha de lozas grandes. El amazzal sigue cuidadosamente la progresión de esta sombra -por la derecha durante la mañana, por la izquierda durante la tarde- observando el alcance de líneas paralelas cavadas en las lozas negras. En este grande libro de piedra están inscritas los derechos de agua que se suceden a lo largo del ciclo diario de la nuba (el turno).

\section{2. ¿Dónde está la clientela de un turismo cultural?}

En el año 2009, Marruecos ha recibido alrededor de 5 millones de turistas extranjeros o no residentes y, una tercera parte, aproximadamente, de las entradas aeroportuarias, se hicieron por Marrakech (23\%) o por Agadir (9\%), lo que representa una proporción superior para los turistas, pues una parte importante de los movimientos por Casablanca son de otra naturaleza (negocios, viajes familiares...). Aunque, en ciertos periodos del año, las llegadas a estas dos ciudades del Sur correspondan con las visitas de Marroquíes que trabajan y viven en el extranjero, una parte apreciable de los 3 a 4 millones de movimientos son de turismo verdadero.

La clientela de los dos polos de atracción es bastante diferente. Marrakech atrae más a gente interesada por las visitas de medinas, de zocos y de artesanía, comple- 
tadas por unas excursiones de un día en el Atlas o a Esauira. Los Franceses y los Españoles son mayoritarios en este turismo con un componente cultural ya importante. Agadir es ante de todo una playa donde los Nórdicos, huyendo de su larga noche polar, vienen a hacer provisión de luz y de calor. Vienen los Alemanes y también los Escandinavos que a principios del decenio del 2000 eran unos 50.000. Sol, arena y night club no significa ausencia total de turismo cultural pero este es muy limitado y se reduce a unas excursiones propuestas por los hoteles a Tarudant, o a Imuzer en el Gran Atlas. Desde hace unos años se ha diversificado el origen de los turistas y ya aparece la gente del Este con los Rusos y los Polacos sobre todo. Esta nueva clientela también viene para disfrutar el sol y divertirse en las boîtes donde sí se sirve alcohol a pesar de la reprobación islámica. Queda muy claro que el tropismo solar y el afán de esparcimiento, en estancias tan breves como una semana, no son muy favorables al desarrollo de un turismo cultural que supone un esfuerzo para descubrir sitios de interés que no se ofrecen en el espacio de una tarde, a la hora del paseo y sin una predisposición mental a la búsqueda cultural. No cabe duda que los turistas que vienen a Marrakech pueden estar más mentalizados y más abiertos a unas posibilidades de ocio cultural pero la brevedad de la estancia y las propuestas de visitas clásicas, más fáciles de organizar para los operadores, reduce mucho la necesidad de buscar temas complicados que necesitan esfuerzos de organización y a veces gastos suplementarios.

La fuente de clientela para un verdadero turismo cultural rural hay que buscarla, probablemente, directamente en el depósito de los países del Norte donde ya se practica este tipo de actividad. Ya existen agencias que proponen circuitos fuera de los caminos trillados, mezclando una experiencia deportiva de senderismo (trekking) con el exotismo de los oasis y las qasabat. Cuando se observa uno las propuestas de estas agencias se nota siempre que el reclamo insista primero en la belleza de los paisajes: "Dunas ondulantes, planicies áridas y rocosas, desfiladeros ocultos, valles frondosos, bosques de cedros, pinos carrascos o alcornoques...Por todas partes, la naturaleza

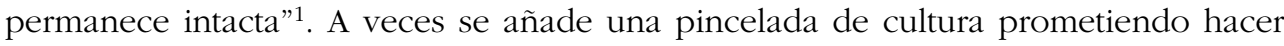
"descubrir un universo de tradiciones fuertes a través de la arquitectura, la indumentaria, los bailes y las costumbres del lugar...". Puede aparecer también la noción de turismo sostenible o de ecoturismo casi siempre ligada a valores ya establecidas como las qasabat de los valles de los uedes Dadés o Todra, al este de Uarzazat. En este caso se observa la aparición de asociaciones locales que buscan, a la vez, un desarrollo económico y una salvaguardia de su patrimonio a través de una cooperación internacional pero apoyándose siempre sobre la posibilidad de senderismo de la región. No cabe duda que, en este caso, se trata del amanecer de un turismo rural y cultural verdadero, pero que debe, para desarrollarse, movilizar muchos más recursos dispersos en todo el país y, sobre todo, procurar que estos puedan ser asequibles físicamente e intelectualmente.

${ }^{1}$ Extracto de una publicidad encontrada en Internet. 


\section{Las condiciones de un verdadero turismo cultural y sostenible}

\subsection{Los obstáculos}

Hemos podido medir la riqueza del patrimonio rural susceptible de favorecer un turismo rural verdaderamente cultural pero hemos visto también que un cierto número de factores constituyen obstáculos para este desarrollo. La dispersión de los sitios y sobre todo la falta de comunicaciones hacia zonas muy aisladas de montaña han impedido la penetración de los turistas desanimados por la dificultad. Esta incomunicabilidad de las zonas con potencial patrimonial fuerte explica también, evidentemente, la ausencia de medios de acogida para los visitantes: falta de hoteles o albergues que no pueden ser sustituidos por casas particulares sin ningún equipamiento sanitario y, de todas formas, donde el grupo familiar no se abre fácilmente para recibir a forasteros. Los operadores turísticos internacionales trabajan sobre todo con grandes hoteles o cadenas de hoteles localizados en las ciudades (Marrakech) o a lo largo de la playa en Agadir. Venden "paquetes" que siempre incluyen estancia hotelera y un cierto número de opciones que generalmente son excusiones breves con regreso al hotel por la noche. Así tienen de sobra complementos bien rodados y pocos onerosos para ellos que los hoteles están encargados de gestionar. Hace cuatro o cinco años hice al director de un gran hotel gadiri la propuesta de un circuito verdaderamente cultural en el Anti-Atlas, para un grupo experimental. Había aceptado con entusiasmo pero cuando llegó el momento de concretar el proyecto se retiró explicándome que, para él, el riesgo era demasiado grande si el operador con quien trabajaba aprendía que había tomado iniciativas al margen de su contrato. La tiranía de los grandes grupos que dominan el mercado es un obstáculo más para el desarrollo de un turismo rural diversificado y flexible. Otro dificultad importantísima es la falta de mediadores serios capaces de dar un contenido verdaderamente cultural al patrimonio presentado a unos turistas ignorantes del significativo histórico y sociológico de los artefactos y de los usos que se observan en el campo. Existe un gran número de guías siempre dispuestos a organizar visitas para ganarse la vida pero son generalmente de pésimo nivel cultural y en la mayoría de los casos son de una generación que no ha vivido en el campo y que desconoce frecuentemente los modos de trabajar en él. Y no insistiré en la dificultad de mediación por la debilidad lingüística de estos guías ocasionales, incluso en francés que normalmente es aprendido ya en la escuela primaria. De otra parte, en los pueblos de la montaña siguen viviendo seres que no pueden aceptar la intrusión de los turistas en su mundo sin recibir algún beneficio de una manera u otra, bien como informante, bien como actor en el desarrollo turístico. 


\section{2. ¿Cómo fomentar un verdadero turismo cultural sostenible?}

De todos los obstáculos que frenan la eclosión de un turismo cultural en una región que posee un potencial tan rico, el más fácil de eliminar es, sin duda alguna, el aislamiento de los sitios de interés. Hasta los últimos años, la montaña, tanto el Anti-Atlas como el Gran-Atlas, era casi impenetrable por carencia de carreteras asfaltadas. En poco tiempo, la situación ha cambiado por completo: las pistas se transforman en carreteras verdaderas y las aldeas más retiradas son asequibles ahora por el teléfono móvil. No solamente, los visitantes pueden llegar más fácilmente sino también los recursos útiles para la acogida de aquellos (alimentación, equipamientos sanitarios...) pueden ser transportados a menos precio. Los obstáculos físicos se borran poco a poco pero hay siempre un desfase entre la apertura vial y la aparición de unos servicios decentes de acogida a los turistas. Son los campos con más antigua conexión los que tienen ahora el hospedaje mejor desarrollado. Un buen ejemplo es el de los oasis marginales del Anti-Atlas oriental (Jbel Sarhro): desde decenios, una carretera asfaltada alcanza, el pueblo de N'Kob donde están precisamente las realizaciones más exitosas de turismo rural, utilizando el patrimonio arquitectónico de las qasabat que aludimos más arriba.

La montaña se abre, pues, y, poco a poco aparecen los medios de acogida con un nivel de calidad que va aumentando. Globalmente los flujos son demasiados débiles como para que la actividad hotelera atraiga a las grandes cadenas o a los operadores internacionales. En la mayoría de los casos, pues, la iniciativa radica en un capitalismo local cuyos recursos no provienen de la agricultura de montaña demasiado pobre sino de alguna empresa comercial en Marrakech, en Agadir o en Casablanca, incluso, a veces del ahorro de toda una vida de trabajo en Europa. Durante mucho tiempo, el dinero ganado afuera ha sido utilizado -y lo es todavía- para expresar con ostentación el éxito económico en la construcción de una casa más vistosa que las pobres moradas del pueblo. La atracción al cliente puede ser todavía bastante aleatoria pero ya se organizan redes de relaciones familiares o de amistades lucrativas que pescan a los clientes para el tiempo de una noche o de una comida. A medida que aumenta el caudal de frecuentación y el nivel de los servicios, también se mejora la herramienta comercial con la intervención de agencias de viaje de las grandes ciudades e, incluso, de los sitios Internet.

No cabe duda que el campo del Sur marroquí se está despertando a un turismo diferente de aquel de sol y playa que domina en Agadir. Si este nuevo turismo de naturaleza y de paisajes saca una parte de su clientela de la masa que acude al litoral, el origen se diversifica cada día más con la venida de pequeños grupos que se dedican casi exclusivamente a un turismo itinerante. ¿Podemos, sin embargo, hablar ya de un turismo cultural verdadero? Para que fuera así sería necesario que el descubrimiento del patrimonio cultural de la sociedad bereber no estuviera abandonado al azar de una parada o a la ignorancia de guías sin formación que compensan con 
anécdotas divertidas. Existen, sin embargo, escuelas de turismo, pero que se dedican más a la preparación de un personal hotelero y de especialistas de gestión turística que a la creación de un verdadero cuerpo de mediadores culturales de alto nivel capaces de crear circuitos con fuerte contenido patrimonial y didáctica eficaz dirigida, en su lengua, a pequeños grupos interesados. Estos circuitos podrían ser temáticos, como lo son, en Europa, los circuitos de las iglesias románicas, por ejemplo. Sería, aquí, una vuelta amplia, en el centro del Anti-Atlas central, de uno o dos días, para visitar los igudar, los graneros colectivos que he descrito más arriba: existe una gran variedad de estos monumentos rústicos. También puede ser una temática en relación con el monte cuyo peso en la vida de las comunidades rurales es todavía grande en las zonas donde el argán se ha conservado y donde queda una fuente apreciable de pasto "aéreo" y de un aceite que se ha puesto de moda en la cosmetología europea. Hay mucho que aprender de usos que han desaparecido de otras zonas mediterráneas donde tuvieron también importancia. Es ciertamente más fácil alimentar un circuito un poco largo con una variedad de temas que aparezcan a lo largo del viaje o de la excursión. Establecer un verdadero programa cultural necesita una preparación esmera tanto del recorrido como del contenido científico de los temas ${ }^{2}$.

\section{Un ejemplo de circuito cultural}

Uno de estos circuitos (Fig. 21) que practiqué varias veces con grupos de alumnos o de colegas puede empezar en el centro de la depresión del ued Sus por una visita de la ciudad de Tarudant (Fig. 13). El interés de Tarudant es similar al que demuestran las demás medinas magrebíes. Pero recorrer sus callejones laberínticos es una buena oportunidad, más allá del sentimiento de exotismo que provoca en el turista, de explicar que esta estructura no es el resultado de una falta de racionalidad de la sociedad urbana sino de la ausencia de administración de la ciudad y de un principio islámico que reconoce la propiedad del suelo al que edifica algo en él (casa, pozo, aljibe etc.). Esta anarquía aparente es también el resultado de una cohesión muy fuerte del grupo familiar que vive en una casa grande construida progresivamente alrededor de un callejón privado, el derb, a medida que se añadían las generaciones bajo la autoridad del patriarca. Puede uno también explicar al turista la presencia bastante importante de manchas agrícolas reliquias dentro del recinto amurallado por la necesidad remota de tierras agrícolas suficientes como para asegurar la alimentación de la población en caso de sitio de la ciudad.

\footnotetext{
${ }^{2}$ Las investigaciones realizadas en el Sur marroquí han sido apoyadas por el Comité Mixte Interuniversitaire Franco-Marocain quien ayudó científicamente y económicamente a la realización de tres programas cuadrienales.
} 


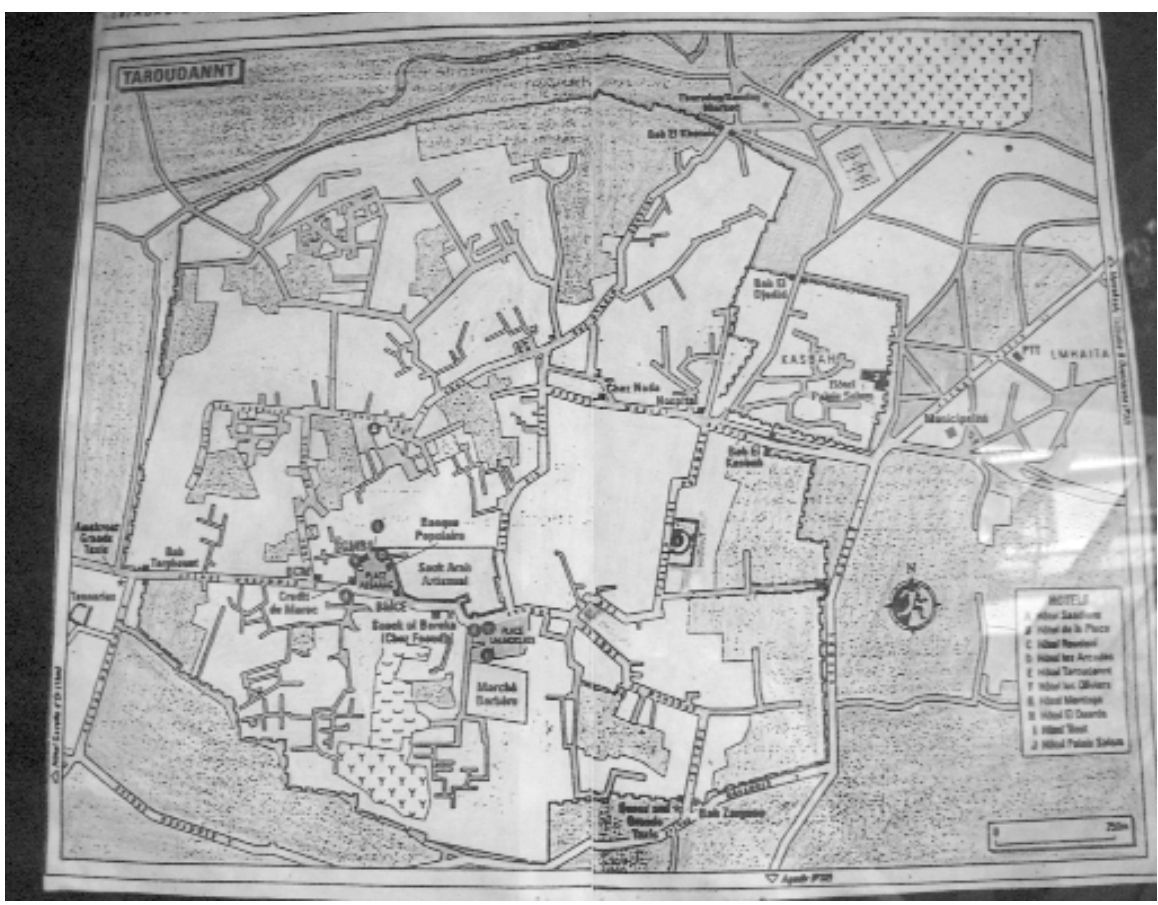

Figura 13. Plano antiguo de la ciudad de Tarudant.

Estando en medio de una medina, es difícil tener una idea clara de su estructura. Un plano como este permite comprender mucho mejor la morfología y el funcionamiento de una ciudad islámica típica. Esta ciudad, antigua capital de la dinastía Saadi, tiene todas las características de una aglomeración que se ha desarrollado sin dirección urbanística. La red de los principales ejes viarios pone en relación las diferentes puertas abiertas en la muralla, pero las ramificaciones de estas calles son, por la mayoría, callejones sin salida, adarves. Son los drub (sing. derb) de las viejas familias que edificaron sus casas según la ley islámica que permite la anexión de un suelo colectivo para edificar en él, según las necesidades de la familia. El resultado es una anarquía evidente del tejido urbano. El colorido claro corresponde al espacio edificado mientras que el más oscuro representa la parte ocupada por el suelo cultivado: en este plano, probablemente de la primera parte del siglo XX, el espacio cultivado representa casi la tercera parte de la superficie total. En la parte sur (parte inferior del plano) uno puede observar la coexistencia de un cementerio musulmán y de otro judío. Casi todas las ciudades magrebíes tenían un importante barrio judío, el mellah.

La aproximación al patrimonio de la montaña se hace por un recorrido de unos 15 a 20 kilómetros en un glacis de piedemonte que sube de manera muy suave cuyo recorrido puede parecer un poco aburrido; presenta, sin embargo, un cierto número de puntos de interés, en el paisaje agrario en particular. En una estrecha franja, a 
ambos lados del río Sus están mezcladas las antiguas facies de las huertas campesinas con el parcelario geométrico de los modernos naranjales; los primeros con sus olivos bordeando parcelas de forma irregular recorridas por la red de las viejas acequias y sembradas de cereales y hortalizas (Fig. 14). Es el contacto abrupto de dos épocas y dos modelos de colonización de la llanura que se extiende entre ambos Atlas que merece unas observaciones y unas explicaciones. Si las grandes superficies esteparias que se extienden hasta el pie de la montaña pueden aparecer como muy vacías, aún cumplen un papel no despreciable en la vida del campesinado que no solamente puede ararlas cuando las lluvias son suficientes sino también aprovechar el monte claro de arganes abastecedor de leña, madera, pasto y sobre todo de aceite que las mujeres extraen de las almendras del hueso con un molinillo de mano. Es también en esta llanura esteparia que se encuentran los restos, a veces impresionantes, de unas

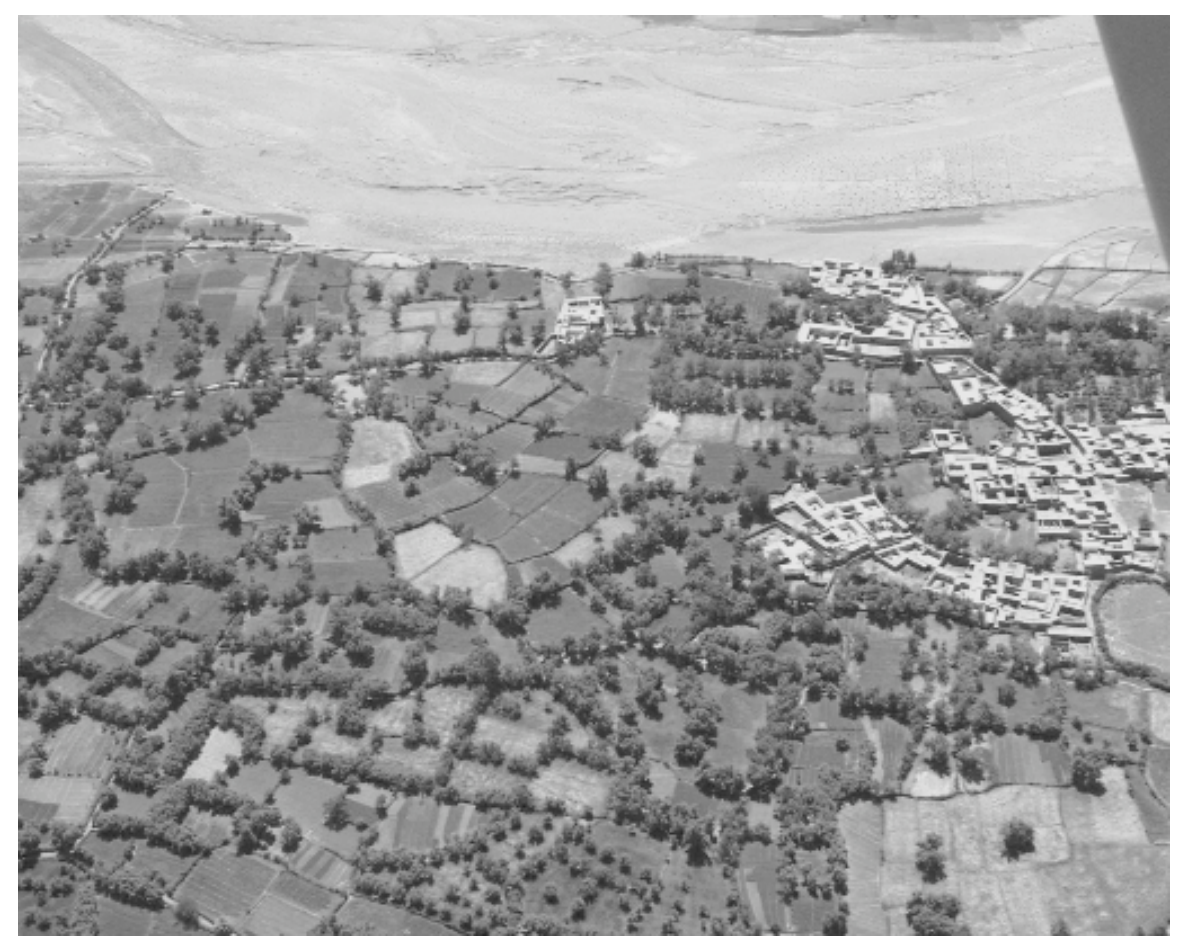

Figura 14. Parte de la vega tradicional del valle del río Sus.

Rodeando un pueblo con sus casas de terrados y su estructura anárquica, la vega (bled seguia) forma un mosaico de piezas irregulares. El suelo lleva cereales y hortalizas de primavera mientras que, en los límites de las parcelas están los viejos olivos. En los bancos de aluviones consolidados del río se aventuran unas parcelas: la conquista puede ser provisional como lo atestiguan las huellas de un parcelario en la parte derecha de la foto. 
fábricas de azúcar de la época Saadi (s. XVI-XVII), en las cuales se molía la caña y concentraba el azúcar que satisfacía a una parte de la demanda europea antes de que el azúcar americano inundara el mercado. Estos restos de una proto-industria da al mediador turístico una excelente oportunidad de hacer una breve historia de la difusión del azúcar, de subrayar la importancia de las relaciones entre el Magreb y Europa y explicar la tecnología azucarera, a la vez que la organización hidráulica asociada. Una visita temprana a uno de los sitios próximos a la carretera de la montaña da a la jornada, de entrada, un carácter patrimonial muy fuerte (Fig. 15).

La penetración en la sierra se hace por una carretera sinuosa que, rápidamente, proporciona al visitante unas vistas espléndidas a la vez sobre la llanura del Sus y

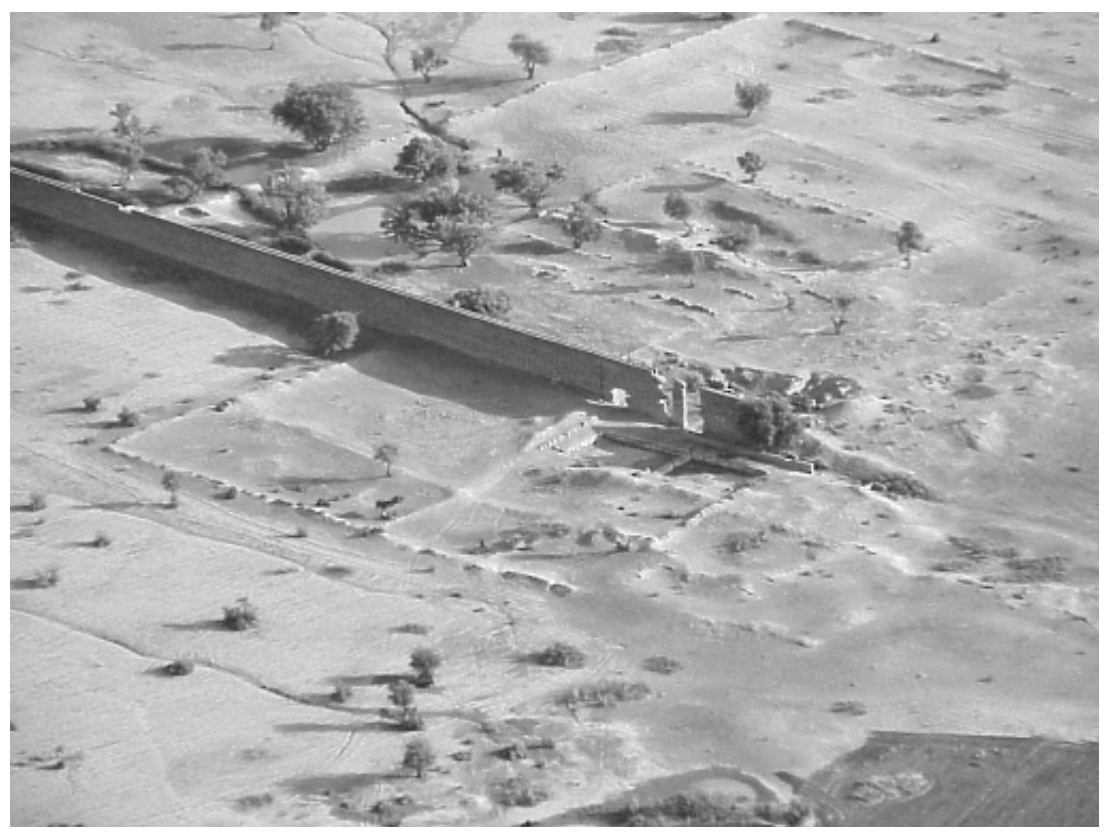

Figura 15. Ruinas de la azucarera de los Ouled Messaoud en el piedemonte del Anti-Atlas central. De la época Saadi (s. XVI-XVII) quedan en el valle del río Sus, los vestigios de 5 o 6 "fábricas" de azúcar. Estas ruinas son los testigos de una actividad proto-industrial en relación con el comercio del azúcar, por intermedio de los Portugueses. Esta actividad controlada por el estado saadí estaba ligada a un cultivo industrial de la caña gracias a un sistema hidráulico que movilizaba, a la vez, los recursos del río Sus y el agua de los acuíferos. En la foto aparece el muro del acueducto que elevaba el agua para mover una gran rueda localizada en la apertura próxima al extremo derecho. A ambos lados del acueducto están las ruinas de la azucarera, la parte principal (molino, hornos, sala de purificación) está detrás del muro. En el primer plano estaban los almacenes de caña así como la balsa para la preparación de los recipientes de cerámica para amoldar el azúcar. 


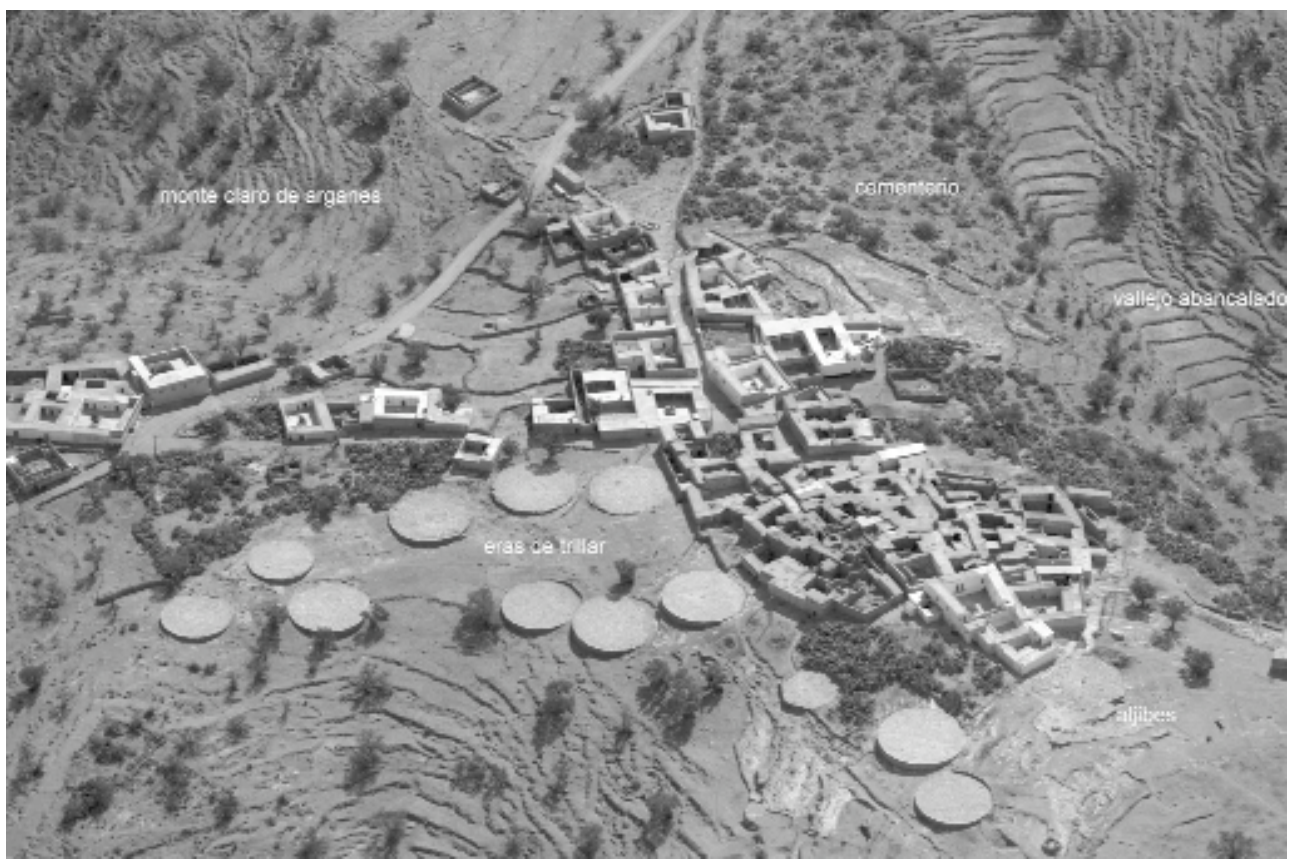

Figura 16. Pueblo (duar) del Anti-Atlas central.

En esta foto están reunidos los elementos principales de un hábitat rural característico. El pueblo es la aglutinación anárquica de un grupo de casas entremezcladas, sobre todo en la parte central más antigua. Podemos notar que los elementos más recientes buscan más espacio e, incluso, quieren apartarse para disfrutar una independencia cada día más deseada por los jóvenes. Como es muy frecuente en esta región, este pueblo es probablemente el hábitat de una gran familia única cuyo dinamismo demográfico ha provocado el crecimiento espontáneo del núcleo primitivo. El grupo ha colonizado sus entornos construyendo sus campos de cereales en las vertientes cubiertas de un monte claro de arganes. Las eras de trillar llaman la atención; un grupo de aljibes es más discreto, así como el cementerio que solo se reconoce por el matorral que ocupa el espacio entre los sepulcros.

sobre las gargantas profundas que se abren en la masa montañosa, con sus pueblos en el fondo o colgados en las vertientes (Fig. 16). Algunos de estos pueblos son perfectamente asequibles desde la carretera para una observación del hábitat y sus anejos: terrazas de cultivo, eras de trillar construidas de manera muy artística (Fig. 18) y un sinnúmero de aljibes familiares alimentados por una compleja red de regueras. La bajada algo acrobática al fondo de un tajo profundo nos hace penetrar en un mundo olvidado hecho de un oasis con su palmeral y el chapoteo delicioso de un riachuelo bajo la vegetación (Fig. 19). Más allá del disfrute poético del encantamiento es el fun- 
cionamiento de una sociedad arcaica y un sistema geográfico en vía de extinción que deben de llamar toda la atención del turista con la ayuda de su mentor. Un ejemplo magnífico existe en la tribu de los Ida ou Limit, al este de la carretera de Igherm, donde el grupo de campesinos formado sobre todo de viejos, mujeres y niños alterna, en función de los trabajos agrícolas, entre la huerta del fondo del valle, donde tiene su pueblo principal y el altiplano donde tiene campos de secano y un pueblo segundario, temporal, con sus eras de trillar. Este sistema es casi un museo, pero un museo vivo con actores que cumplen su propio papel. Este sistema moribundo es el testigo de una civilización que dominó en una montaña muy humanizada; nos ayuda a comprenderla y nos da el deseo de conservarla gracias al apoyo económico que puede representar el turismo cultural. Es un buen ejemplo de lo que puede ser el desarrollo sostenible real frente a aquel, idealizado, de los discursos académicos. El complemento económico recibido por el viejo hortelano que conduce a los grupos por el oasis explicándolos el turno de agua, la nuba o tauala, la fertilización a mano de las flores de las palmeras o el funcionamiento de un pequeño molino de acequia no es del todo desdeñable para un hombre que no tiene ningún tipo de ayuda pública. Pero el impacto es más significativo, todavía, si unas familias del pueblo preparan y sirven una comida tradicional al grupo y, aún más, si pueden acogerlo para una noche en la gran sala de recepción de las casas tradicionales. Esta función "hotelera" significa, sin embargo, de parte de los hospederos, un esfuerzo de inversión para modernizar el equipamiento sanitario sin desnaturalizar la estructura del hábitat tradicional. El peligro de un impacto negativo sobre el patrimonio no puede ser excluido, sin embargo, los ejemplos conocidos en la parte este, en la zona de las qasabat, demuestran que una modernización cuidadosa e inteligente, puede preservar el patrimonio arquitectónico sin perjudicar la eficacia funcional de las transformaciones.

La pernoctación en un pueblo, en medio de un circuito, tiene la ventaja de dar más tiempo para disfrutar el ambiente y profundizar las observaciones. Las etapas cortas permiten también más paradas improvisas para aprovechar la ocurrencia de un fenómeno imprevisible como una escena de siembra y labranza (Fig. 17), de cosecha, de construcción de un aljibe o de la cocción del pan en un horno familiar (Fig. 20). El encuentro, en la carretera, o próximo a ella, de un zoco semanal, puede dar, también, la ocasión de explicar la organización y funcionamiento de estos mercados rurales. El nombre de los zocos, ligado estrictamente al número del día de la semana en el cual tienen lugar -suq el arbaa es un zoco del miércoles o sea del día cuarto- permite, sin embargo, prever la posibilidad de una visita en un circuito preparado.

Muchísimos fenómenos son así observables a lo largo de un itinerario [mezquitas campestres, cementerios, zauaya, quba(s)], pero su contemplación no volverá a ser realmente cultural sin las explicaciones de un guía culto que sepa colocar cada fenómeno en su contexto societal o religioso. Uno de los más atractivos es el granero for- 


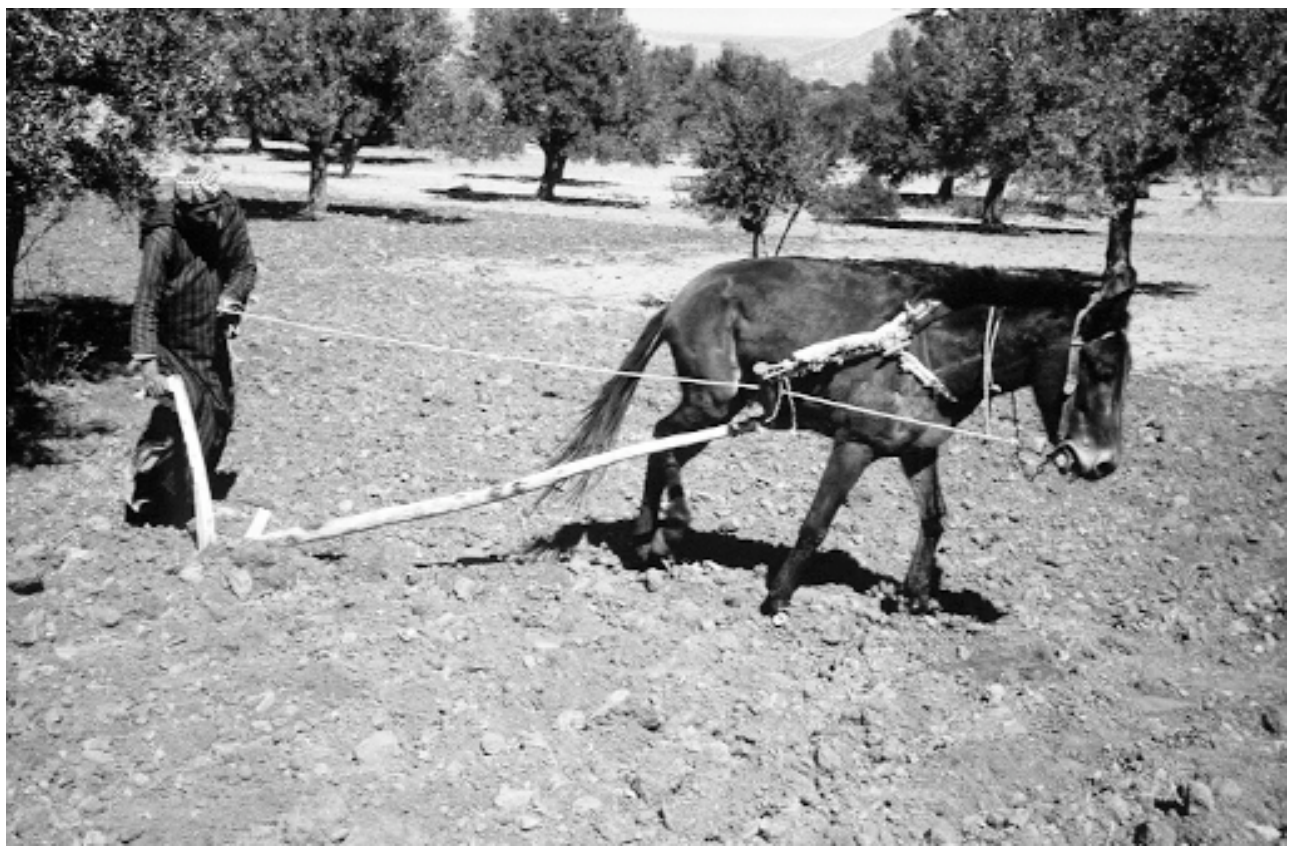

Figura 17. Labranza con el arado romano en el Gran Atlas occidental.

Si no fuera por el vestido del campesino esta escena podía observarse en muchas partes de España decenios atrás. El paisaje es muy parecido al de los encinares de Castilla o Andalucía, pero aquí son arganes que cumplen un papel semejante. Hasta la mecanización reciente de las grandes Ilanuras, el arado de vertedera no ha sido introducido. El campesino -el fellah- ha sembrado antes de arar para cubrir las semillas.

tificado -el agadir- que está presente en gran parte del Anti-Atlas occidental. Cualquier circuito elegido puede comprender uno o varios de estos monumentos rurales: varios existen en el circuito que hemos elegido, en particular alrededor del pueblo de Igherm, de diferentes formas y estructuras, a veces todavía con su portero que acoge a los visitantes con un té de bienvenida.

El desarrollo de un turismo rural cultural de ninguna manera puede ser macizo. Solo puede difundirse de una manera progresiva a medida que se abren la montaña y las mentalidades de una sociedad introvertida. Visitantes del Norte acostumbrados a un turismo rural y cultural pueden representar la clientela potencial de este tipo de turismo, siempre que esté asegurada la accesibilidad y la acogida material en buenas condiciones sanitarias. Los medios modernos -teléfono móvil e Internet- que se desarrollan de una manera rápida en las comarcas más retiradas, contribuyen, sin duda 


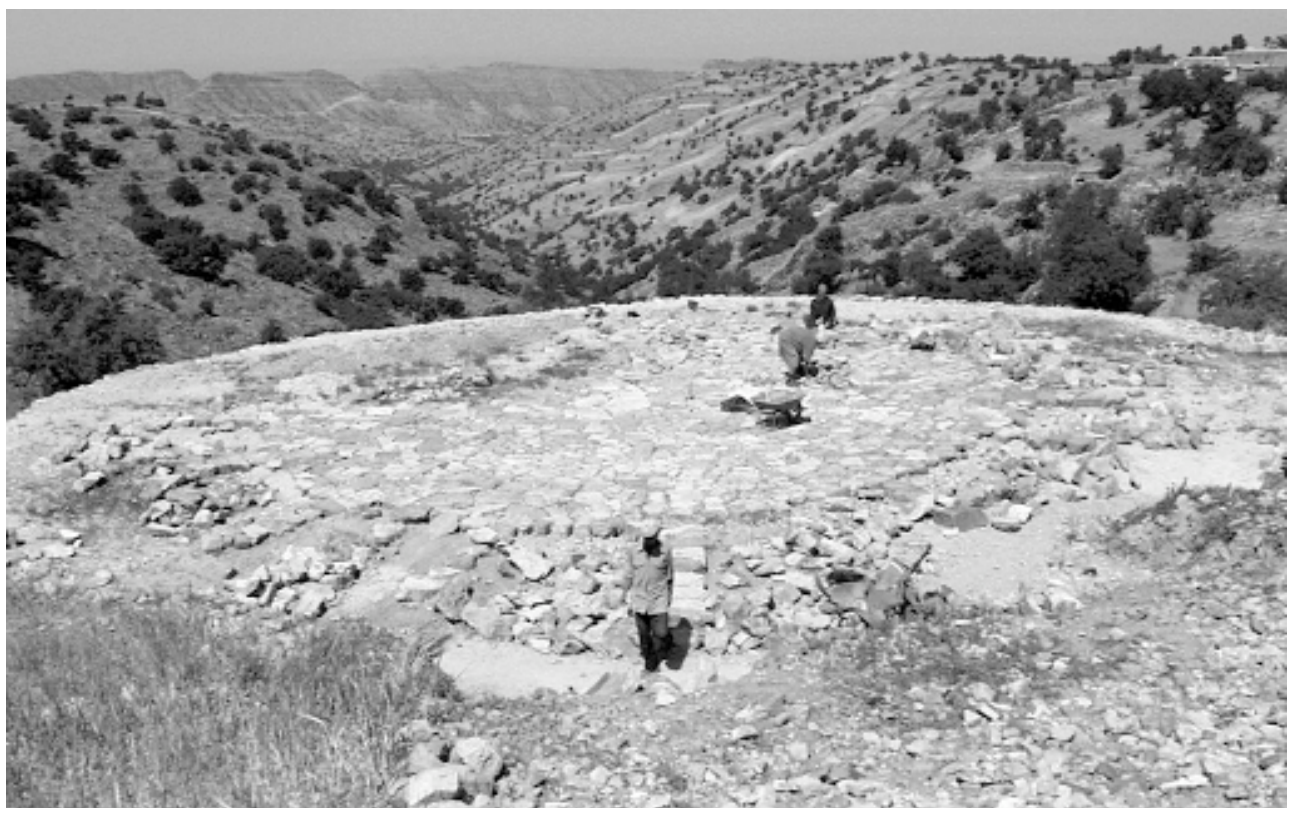

Figura 18. Era de trillar en construcción en el pueblo de Imariden (Anti-Atlas central). A principios del siglo XXI, la gente del campo sigue construyendo las era de trillar en las cuales, manadas de 10 o 12 burros giran para trillar con sus pies. Son obras de arte popular que merecen atención de parte de los visitantes.

alguna, a la propagación de esta forma de turismo. Sin embargo, un turismo cultural de calidad no puede prescindir de una información también de calidad con mediadores culturales provistos de una buena formación patrimonial y geográfica así como de un nivel lingüistico suficiente como para dar explicaciones claras a los visitantes extranjeros. Pero, además, la sostenibilidad de este turismo supone, a la vez, que el beneficio recaiga en la población local e, incluso, que contribuya al retorno de gente joven dinámica y emprendedora y que anime una voluntad fuerte de salvaguardar un patrimonio en peligro de destrucción (Fig. 22). El turismo cultural no puede ser una panacea que resucite una región que ha perdido gran parte de su sangre humana, pero sí puede contribuir a evitar un abandono total que parecía inevitable hace poco, siempre que el desarrollo moderado, pero sostenible, proceda de iniciativas endógenas con la preocupación muy fuerte de los actores por la protección de su medio ambiente y la riqueza patrimonial fuentes de riqueza. 


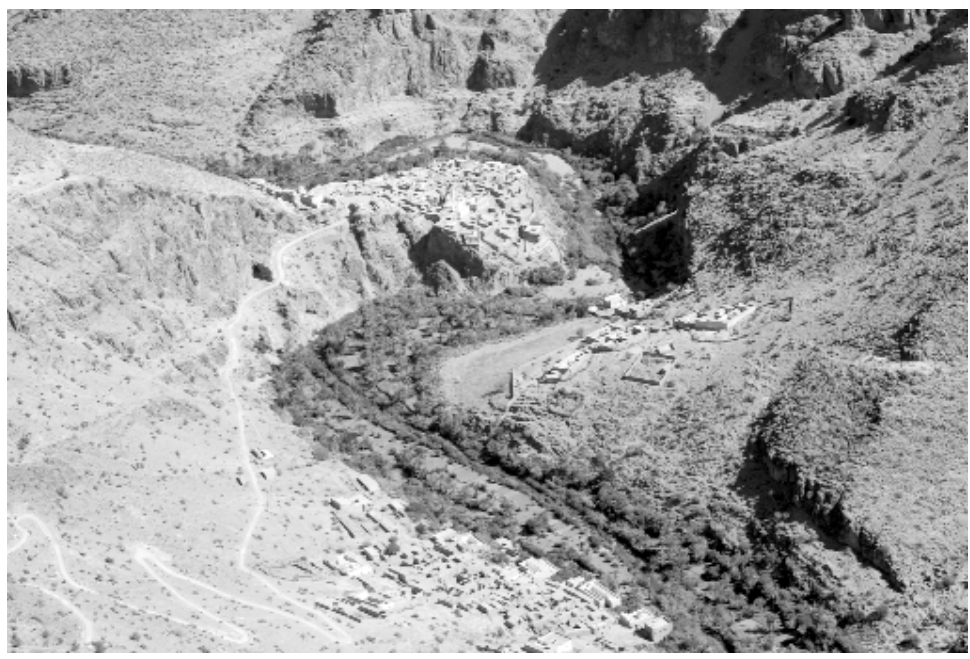

Figura 19. El oasis-palmeral de los Ida ou Limit.

Este paisaje es uno de los más hermosos del Anti-Atlas central. El palmeral aprovecha los nacimientos de agua que aparecen en el fondo de la garganta abierta en la masa de calizas paleozoicas de esta parte de la montaña. El pueblo aprovechó el lóbulo del meandro. Los turistas pueden aquí disfrutar y aprender sobre un modo de vida campesina que ha desaparecido casi por completo de Europa.

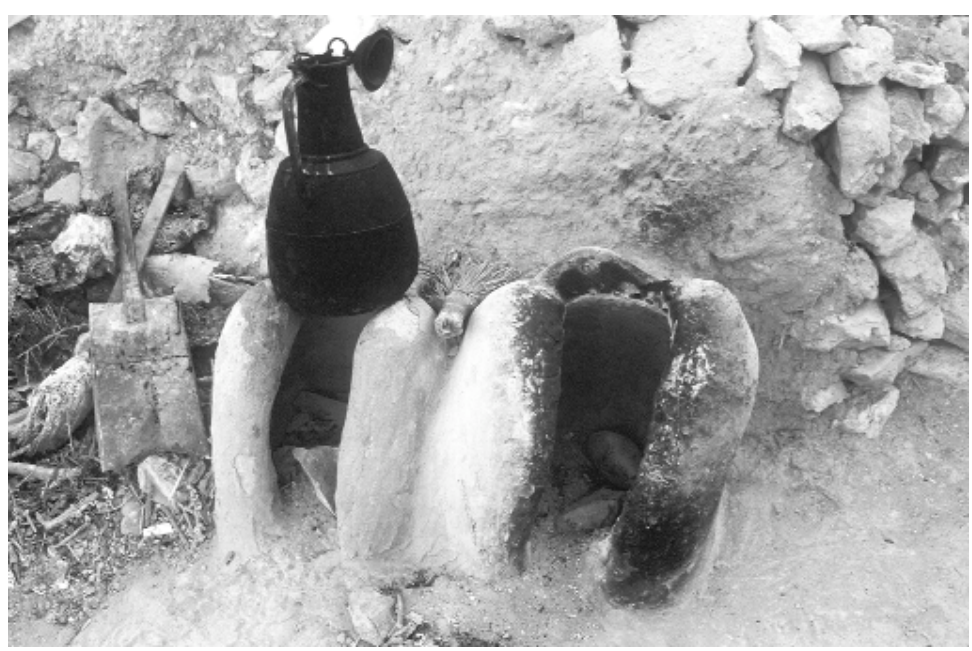

Figura 20. Hornos de pan familiares del Anti-Atlas occidental.

Este tipo de horno de pan permite al ama de familia preparar, cada mañana, un pan ázimo, pegando la pasta fina en la pared vertical del horno previamente calentado. Otros tipos de hornos existen en el interior de la casa. 


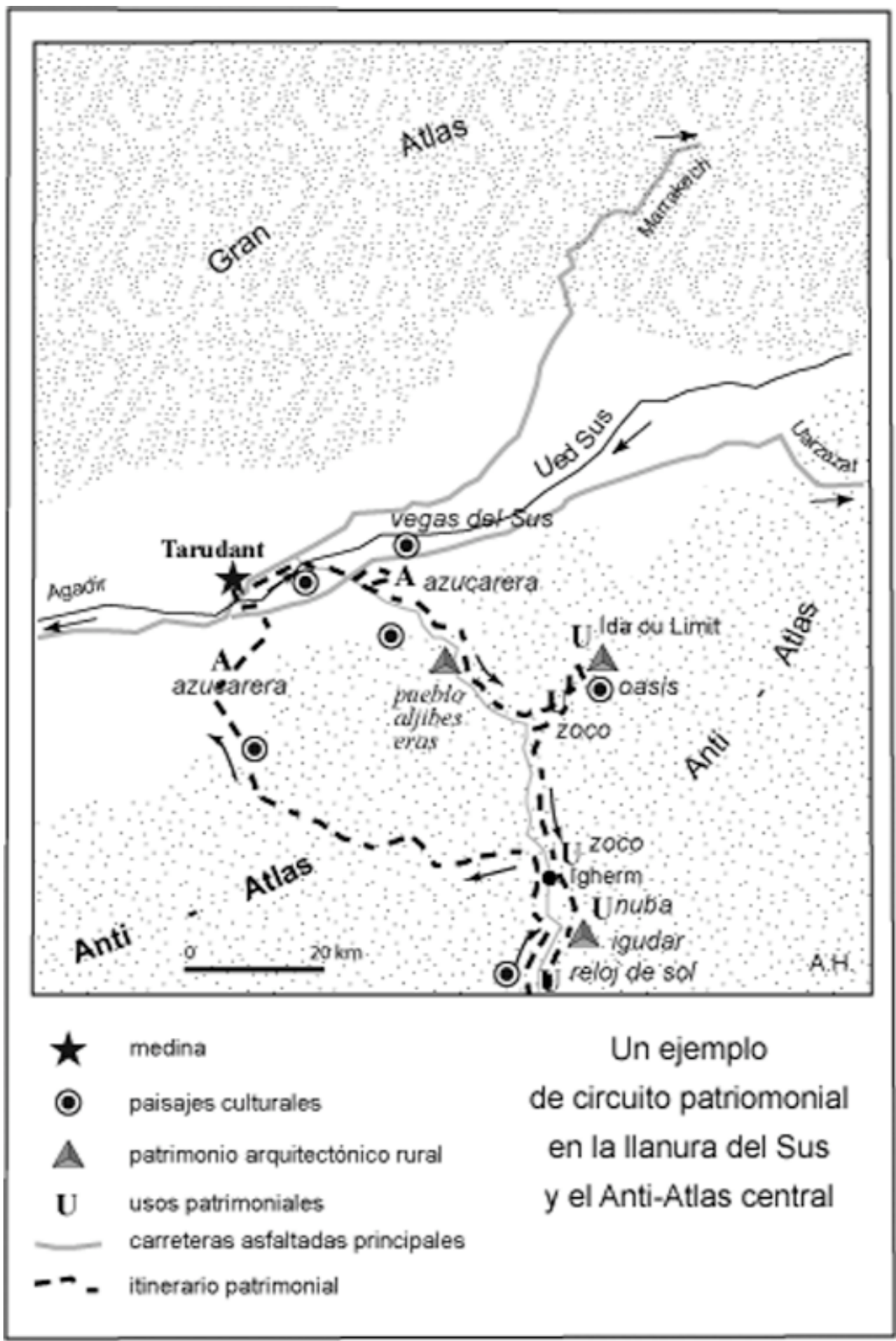

Figura 21. Un ejemplo de recorrido cultural en el Anti-Atlas central y una parte de la llanura del Sus. Este itinerario puede alimentar una, dos o tres jornadas de visitas, en función del tiempo disponible y sobre todo de las posibilidades de acogida para pernoctar. Los puntos de interés indicados en el mapa no son exhaustivos. 


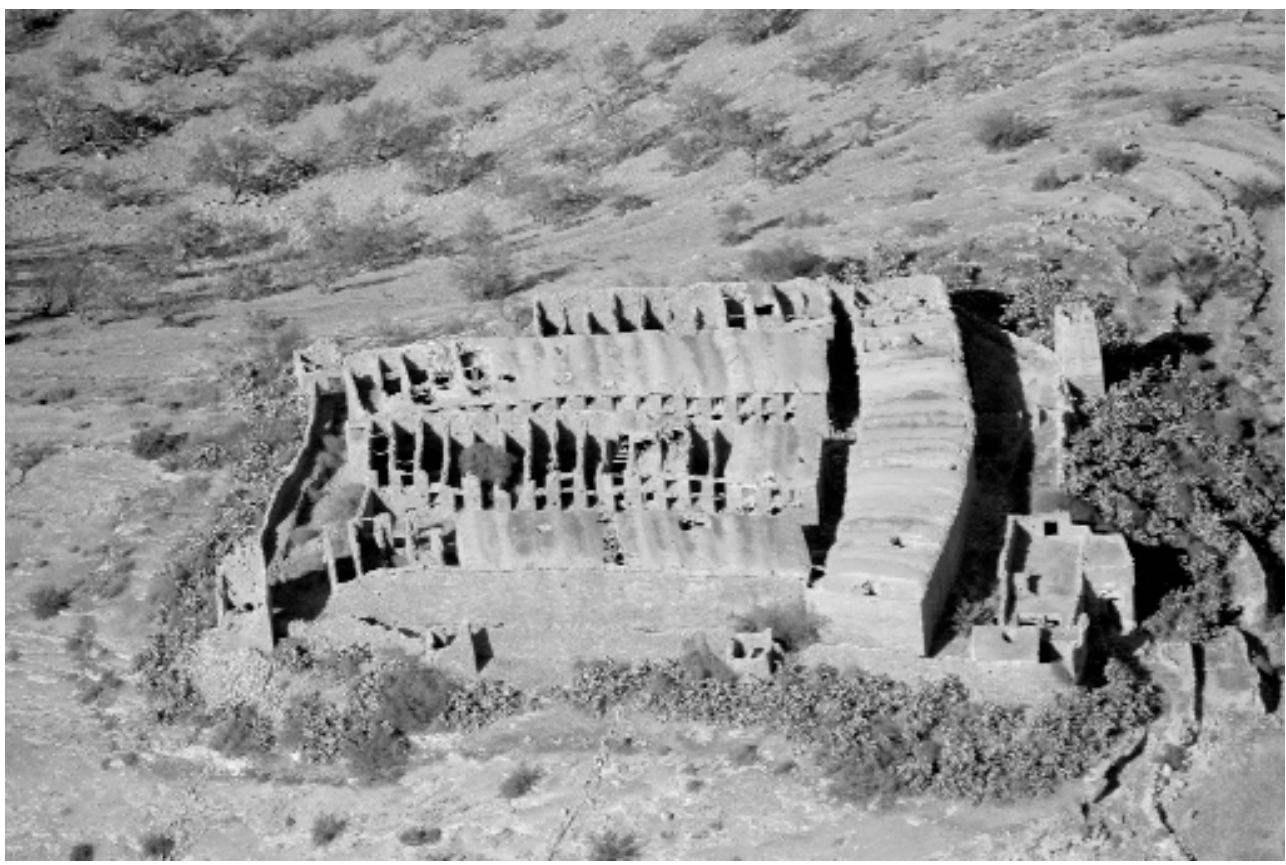

Figura 22. Gran agadir arruinado del Anti-Atlas occidental.

Uno de los más grandes y más hermosos igudar del Anti-Atlas está, desgraciadamente, casi totalmente arruinado. La mayoría de los terrados de los compartimientos se han hundido. La recuperación de este edificio aparece como muy difícil. La única ventaja de esta situación es que, en esta foto aérea, aparece claramente la estructura íntima del granero. Los demás elementos están todavía bastante bien conservados (torre y casa del portero).

\section{Glosario}

Abudrar (plur. ibudraren): palabra bereber para nombrar el hombre de la montaña, el montañés.

Agadir (plur. igudar): granero fortificado colectivo utilizado por las comunidades campesinas para resistir las razias de las tribus nómadas. Están concentrados sobre todo en el Anti-Atlas occidental y central, en el Gran Atlas central y en el macizo volcánico del Sirua.

Amazzal: "el que corre". Es el regador que organiza y vigila la nuba-el turno de agua- en las vegas y huertas de regadío comunitario. En los pueblos donde puede todavía ejercer su oficio es un personaje importante considerado como un sabio por su conocimiento del sistema hidráulico. 
Amín (pl. omana): portero. Es -era sobre todo- un hombre de confianza que estaba encargado de vigilar los igudar. Tenía la llave de la puerta principal del agadir donde vivía con su familia. Controlaba todos los movimientos de entrada y salida al granero.

Anrar (pl. inraren): era de trillar, a veces, como las antiguas eras ibéricas, construidas con lozas ensambladas en mosaico.

Derb (plur. $d r u b)$ : callejón sin salida sobre la cual se abren las puertas de las moradas de una gran casa linajera, en las medinas o en los pueblos. Puede ser en parte cubierto y frecuentemente unos bancos de piedra están dispuestos a ambos lados para acoger a los varones más añosos del amplio grupo familiar.

Haratín (sing. hartani): poblaciones negras o mestizas que fueron introducidas como esclavos, desde las regiones del Sahel sudanés, a los oasis del Sur marroquí para constituir una mano de obra abundante y barata. Cumplían las faenas del campo dominado par los nómadas bereberes que conducían su ganado de las márgenes saharianas hasta los pastos de verano del Gran Atlas.

Ineflás (sing. aneflús): guardias armados que durante las épocas de inseguridad estaban encargados de defender los igudar. Era una milicia compuesta de miembros varones de las familias que utilizaban el granero.

Nuba (pl. nubat): en árabe, el turno de agua en una vega o huerta de regadío tradicional. Los régimenes de repartición del agua pueden ser muy diferentes de un lugar a otro, así como la relación jurídica entre la tierra y el agua. Los dos elementos pueden ser indisolublemente unidos en el régimen llamado jmaa, o sea comunitario, pero pueden también ir por separado y ser objetos de compras-ventas independientes. La repartición puede ser mucho más compleja en la segunda situación dificultando el trabajo del amazzal (el regador) que juega un papel importantísimo en el grupo. (Ver tauala)

Qasba (pl. qasabat): casa grande que parece a un castillo con cuatro torres en los esquinas. Las qasba(s) son abundantes en el ámbito de los qsurdonde marcan una diferencia social evidente entre los haratin y los Bereberes blancos que fueron sus dueños. No se debe de confundir qasba y qsar (ver la palabra), lo que es frecuente, aunque, a veces, las qasba(s) pueden ser reunidas en pueblos fortificados como los qsur.

Qsar (plur. qsur): pueblo fortificado del sureste particularmente presente en los valles de los ríos Dadés y Draa, así como en el Tafilalet. Frecuentemente son de planta regular y son el hábitat de comunidades de haratín (ver la palabra) que cultivan los palmerales como jameses, es decir colonos recibiendo la quinta parte de la cosecha. 
Quba: sepulcro de una persona piadosa o de un marabuto que se reconoce porque está a menudo dominado por una cúpula o quba. Estos monumentos bastante humildes están frecuentemente dispersos en el campo o edificado en medio de un cementerio.

Tanast: (pl. tanasin): tazón de cobre que la comunidades de regantes utilizaban -utilizan todavía, a veces- para medir el tiempo durante la nuba (ver la palabra). Se trata de un reloj de agua cuya unidad de tiempo corresponde al tiempo que tarda en hundirse totalmente en una pequeña balsa de agua o un cubo grande. Está manejada por el regador mayor (amazzal) que cuenta las inmersiones a lo largo del día, avisando a los beneficiarios del inicio y terminación de su turno. El derecho al agua se expresa en un cierto número de tanasín y no en minutos u horas.

Tanutfi: (pl. tinudfay) palabra bereber para nombrar el aljibe subterráneo en el cual se recupera el agua de lluvia en las comarcas sin nacimientos y sin capa freática asequible. El agua almacenada alimenta a las familias durante la muy larga temporada veraniega con una bebida de mala calidad que la gente saneaba, hasta hace poco tiempo, con cal viva, haciéndolo hoy con hipoclorito de sosa.

Tauala (pl. tiualiuin): Es la nuba en bereber.

Zauia (pl. zauaya): cofradía y edificio religiosos ligados al sepulcro de una persona piadosa o santón. Las zauaya tienen una mezquita y sobre todo una escuela coránica donde acuden personas piadosas y jóvenes que aspiran a ciertas funciones clericales.

\section{Bibliografía}

Humbert, A. (2000) Le système hydraulique du Souss et la culture de la canne à sucre, Actes du colloque Eau, environnement et histoire des paysages dans le Sous, Taroudant, novembre 2000, Nancy, Université de Nancy 2, CD-Rom, 2002.

Troin, J.F. (dir) (2002) Maroc. Régions, pays territoires, Paris, Maisonneuve et Larose, $502 \mathrm{p}$.

Humbert, A. (2003) L'Anti-Atlas : une montagne paysanne moribonde?, in Crises et mutations des agricultures de montagne,
Clermont-Ferrand, Université Blaise Pascal, CERAMAC, p. 61-72.

Humbert, A. (2006) Comment mesure-t-on l'eau d'irrigation dans les communautés traditionnelles du Maroc méridional ? in P. Cressier (dir), La maîtrise de l'eau en alAndalus. Paysages, pratiques et techniques, Madrid, Collection de la Casa de Velázquez, p. 313-325.

Humbert, A. (2007) Terroirs patrimoniaux andalous: une cohabitation possible avec l'agriculture de contre-saison?, Méditerranée, 109, 85-91. 
Wackermann, G. (2008) Le développement Boujnikh, M. y Humbert, A. (2010) L'eau dans durable, Paris, Ellipses, col. Carrefours, le bassin du Souss, Norois, 1, 1-13. $493 \mathrm{p}$. 